\title{
CONTROL OF THE PUBLIC DEBT: A REQUIREMENT FOR PRICE STABLITY?
}

Michael Woodford

NBER Working Paper 5684

\section{NATIONAL BUREAU OF ECONOMIC RESEARCH 1050 Massachusetts Avenue \\ Cambridge, MA 02138 \\ July 1996}

I would like to thank Ben Bernanke, Michael Bordo, Guillermo Calvo, Michael Dotsey, Peter Kenen, William Perraudin, Julio Rotemberg, Erich Streissler, and Lars Svensson for helpful discussions, Eduardo Loyo for research assistance, and the National Science Foundation (U.S.) for research support. I would also like to thank Bob King and Mark Watson for supplying the program described in King and Watson (1995). This paper is part of NBER's research programs in Economic Fluctuations and Growth, and Monetary Economics. Any opinions expressed are those of the author and not those of the National Bureau of Economic Research.

(C) 1996 by Michael Woodford. All rights reserved. Short sections of text, not to exceed two paragraphs, may be quoted without explicit permission provided that full credit, including (C) notice, is given to the source. 


\title{
CONTROL OF THE PUBLIC DEBT: \\ A REQUIREMENT FOR PRICE \\ STABILITY?
}

\begin{abstract}
The paper considers the role of limits upon the permissible growth of public debt, like those stipulated in the Maastricht treaty, in making price stability possible. It is shown that a certain type of fiscal instability, namely variations in the present value of current and future primary government budgets, necessarily results in price level instability, in the sense that there exists no possible monetary policy that results in an equilibrium with stable prices. In the presence of sluggish price adjustment, the fiscal shocks disturb real output and real interest rates as well.

On the other hand, shocks of this kind can be eliminated by a Maastricht-type limit on the value of the public debt. In the presence of the debt limit (and under assumptions of frictionless financial markets, etc.), "Ricardian equivalence" holds, and fiscal shocks have no effects upon real or nominal variables. Furthermore, an appropriate monetary policy rule can ensure price stability even in the face of other kinds of real shocks. Thus the debt limit serves as a precondition for the common central bank in a monetary union to be charged with responsibility for maintaining a stable value for the common currency.
\end{abstract}

\author{
Michael Woodford \\ Department of Economics \\ Princeton University \\ Princeton, NJ 08540 \\ and NBER
}


Reduction of government deficits and controlling the rate of growth of the outstanding public debt has moved to the forefront among the economic policy challenges facing many of the leading industrial nations in recent years. This has come to be of particular concern among the members of the European Union, nearly all of whom must modify their present courses if they are to satisfy the requirements laid down in the Maastricht treaty for participation in the proposed European monetary union. An obvious question raised by the fiscal requirements of the Maastricht treaty - and a pressing one, given the difficulties that many aspiring members of such a union face in satisfying these requirements - is why controls over the degree to which governments resort to deficit finance should be essential to a successful monetary union. ${ }^{1}$

Indeed, conventional macroeconomic models provide little reason to suppose that the public debt is an important determinant of the value for a country's currency, and by extension, little reason to suppose that individual member nations' fiscal policies should interfere with the ability of a common European central bank to maintain a stable value for a common currency. Such a conclusion might be reached on any of several grounds. First, some would maintain that monetary policy is the sole, or at least the main, determinant of the equilibrium price level; such a strong monetarist position implies that control of fiscal policy is unnecessary in order to achieve price stability, as long as fiscal policy can be prevented from having any effect upon monetary policy. Monetarists recognize that fiscal problems are often the root cause of high inflations, owing to the seignorage revenues that can be obtained from rapid money growth. But it is often doubted that such concerns have much effect upon monetary policy in low-inflation countries (where seignorage revenues must remain a small fraction of the government budget, unless a truly radical change in policy occurs); and in any event monetarists generally argue that it suffices to ensure the independence of the central bank and that it is charged with a proper mission, in order to achieve price stability, regardless of the nature of fiscal policy.

Second, even if one admits a richer menu of factors as determinants of aggregate demand, it may be argued that government deficits should be one of the least important, because of the doctrine of "Ricardian equivalence" (Barro, 1974, 1989). It is argued that if households correctly understand the future consequences of current changes in the government's budget, they will adjust private saving so as to exactly offset any change in the level of national saving, with the consequence that there is no change in aggregate demand at existing prices and interest rates. It follows (though such analyses are often conducted in complete abstraction from the determination of nominal variables) that government deficits should cause no disturbance to price stability.

And finally, even if one admits that the government budget is able to affect aggregate demand, one may nonetheless argue that an appropriate monetary policy should be able to ensure price stability, by offsetting the effects of fiscal policy on

\footnotetext{
${ }^{1}$ The reasonableness of these requirements has been challenged by many academic commentators; see, e.g., Buiter et al. (1993).
} 
aggregate demand as necessary. (The standard textbook IS-LM-AD analysis clearly implies this: the central bank need simply adjust the level of nominal interest rates so as to coincide at all times with the point on the "IS curve" corresponding to potential output.) Under such an analysis, fiscal instability complicates the task of the central bank, but a desire for price stability need not require that fiscal policy be subordinated to that end.

I shall argue that these analyses all understate the obstacle posed to price stability by failure to control the path of the public debt. I will argue not only that variations in the government budget can be an important source of macroeconomic instability, but that the instability is not eliminated when the central bank follows a monetary policy rule that is completely unresponsive to the size of the public debt. Nor may it be eliminated simply by an appropriate monetary policy response to the fiscal shocks.

In the presence of nominal rigidities, as are assumed in the model developed here, the fluctuations in aggregate demand resulting from fiscal shocks cause variations in the level of real economic activity and in real interest rates, as well as variations in the rate of inflation. These effects thus represent a violation of Ricardian equivalence. This occurs despite the fact that the analysis assumes rational expectations, identical infinite-lived households, pure lump-sum taxation, and frictionless financial markets. These idealized assumptions are made exactly to clarify that the channel through which fiscal policy affects aggregate demand here is a different one than those stressed in more familiar analyses (having to do with myopic expectations, intergenerational redistribution, government borrowing on terms not available to private households, and the like), and so not subject to the familiar critiques.

The reason that the usual arguments for Ricardian equivalence fail here lies elsewhere. These arguments assume that fiscal policy necessarily has the property that whenever the level of the outstanding public debt changes, the present value of future government surpluses changes by exactly the same amount, regardless of the path that prices and interest rates may follow. And when fiscal policy has this "Ricardian" property, it is indeed true (under the idealized assumptions referred to above) that changes in the path of the government budget and of the public debt have no effect upon aggregate demand. But there is no reason that fiscal policy must be Ricardian in this sense; a wide range of non-Ricardian policy rules are perfectly consistent with rational expectations equilibrium, and it is in particular hardly obvious that governments that appear to be unable to rein in chronic budget deficits are nonetheless capable of ensuring that the condition just mentioned will always be satisfied. If fiscal policy is not Ricardian, and shocks that change the expected present value of current and future government budgets occur, a rational expectations equilibrium may well exist, but will not involve stable prices or output. This is because under a non-Ricardian' regime, fiscal shocks do change households' intertemporal budget constraints, at what would otherwise have been equilibrium prices and interest rates; hence markets fail any longer to clear at those prices. ${ }^{2}$ An explicit example of

\footnotetext{
${ }^{2}$ This channel for the effects of fiscal variables is discussed in the context of a simpler model in
} 
rational expectations equilibrium under such a regime is presented below.

These results provide a reason for a country that cares about price stability to be concerned about the prospect of sharing a common currency with a country that is unable to control its public debt, in the precise sense of following a Ricardian fiscal policy rule. Adherence to a Ricardian fiscal policy by one country, or even maintenance of a balanced budget at all times, will not protect it from price level instability generated by variations in the budget of the other government, even if the monetary policy rule adopted by the common central bank ignores the paths of both countries' public debts. The only way that the fiscally responsible country could insulate itself, in principle, from instability of that kind would be by varying its own budget surplus in such a way to counteract the budget variations of the other country, so as to keep the total public debt of the monetary union on a steady path. But this would amount to offering to finance the other country's budget deficits, so as to eliminate the need for borrowing - a type of blank check that no government will be willing to extend to neighbors lacking in fiscal discipline! The analysis thus provides some support for the concerns of the architects of the Maastricht treaty with the viability of a monetary union in the absence of demonstrated capacity for fiscal discipline on the part of all member countries.

The paper proceeds as follows. Section 1 presents a simple closed-economy general equilibrium macroeconomic model, in the context of which the analysis is conducted. Section 2 illustrates the effects of fiscal shocks upon inflation, output, and interest rates in the case of a non-Ricardian fiscal regime. Section 3 discusses the way in which a constraint upon fiscal policy - specifically, a commitment to keep the public debt within some ceiling forever - could eliminate this source of instability, and make it possible for price stability to be achieved by a suitable monetary policy. Finally, section 4 extends the analysis to the case of a monetary union with independent national fiscal policies.

\section{A General Equilibrium Model with Sluggish Price Adjustment}

In order to assess the degree to which an appropriate choice of monetary policy is able to achieve price stability, it is useful to adopt a theoretical framework in which pricelevel instability affects the real allocation of resources. For that reason, I here develop a simple general equilibrium model with nominal price rigidity, as a result of which

Woodford (1995). There the concern is solely with price-level determination in a world of perfectly flexible prices, with both output and real interest rates exogenously given. See also the related analyses of Leeper (1991), Sims (1994, 1995), and Bergin (1995), to which the same comment applies. The introduction here of nominal price rigidity allows for a richer analysis. In particular, the nominal rigidities allow for variation in real interest rates, which has important consequences for the interaction between monetary policy and the government's budget. 
the level and pattern of economic activity is distorted by price level variations over time. The model of nominal price rigidity that I will use is a discrete-time variant of a model introduced by Calvo (1983). ${ }^{3}$ In this model, it is assumed that each period a fraction $1-\alpha$ of goods suppliers get to set a new price, while the remaining $\alpha$ must continue to sell at their previously posted prices (for some $0 \leq \alpha<1$ ). The suppliers that get to set new prices are chosen randomly each period, with each having an equal probability of being selected. Thus the probability of a price change is independent of both the time that has elapsed since the last price change, and of the degree to which costs and other market conditions have changed since then. This is obviously an unrealistic simplification, but it does make the model's dynamics very simple (in particular, only a small number of state variables need be tracked over time), while allowing for an arbitary degree of price rigidity (anywhere between complete price flexibility, in the limit of $\alpha=0$, and complete price rigidity, in the limit as $\alpha$ approaches 1).

Let the economy consist of a contimuum of identical infinite-lived households, indexed by $j \in[0,1]$, each of which specializes in the production of a single differentiated good, of which it is the monopoly supplier. ${ }^{4}$ There is thus also a continuum of differentiated goods each period, indexed by $z \in[0,1]$, with $z=j$ denoting the good supplied by household $j$. Each household consumes all of the goods, and indeed household preferences over consumption bundles are assumed to be identical. Each household's own purchases are only an infinitesimal share of the total demand for any of the goods that it produces, and the prices that it sets make only an infinitesimal contribution to its overall costs of obtaining consumption goods; hence the household sets prices without regard to the effect of such decisions on its own cost of obtaining consumption goods.

Let us assume that each household $j$ seeks to maximize a lifetime objective

$$
E\left\{\sum_{t=0}^{\infty} \beta^{t}\left[u\left(C_{t}^{j}+G_{t}\right)+v\left(M_{t}^{j} / P_{t}\right)-w\left(y_{t}(j)\right)\right]\right\},
$$

where $u$ and $v$ are increasing concave functions, $w$ is an increasing convex function, and $\beta$ is a discount factor between 0 and 1. Here $y_{t}(j)$ is the household's supply of

\footnotetext{
${ }^{3}$ This has become something of a standard baseline model of nominal rigidity in quantitative general equilibrium business cycle models. See Yun (1994), Kimball (1995), King and Watson (1996), and King and Wolman (1995) for examples. The exposition given here does not follow exactly any of those cited; in particular, unlike any of those papers, it does not explicitly model firms, the labor market, or the dynamics of capital accumulation, in order to focus more clearly upon the equilibrium relations that are of central importance for the issues addressed here.

${ }^{4}$ The model is one of monopolistic competition, so that suppliers have the power to set prices, following Svensson (1986) and Blanchard and Kiyotaki (1987). Like these authors, we model monopolistic competition along the lines of Dixit and Stiglitz (1977). The assumption of "yeoman farmers", as, for example, in Obstfeld and Rogoff (1995), allows us to model the pricing/supply decision without having to explicitly introduce firms and factor markets. An aggregate supply relationship of essentially the same kind can be derived in the more explicit model; see, e.g., Yun (1994).
} 
its product, and $C_{t}^{j}$ is an index of the household's consumption defined by

$$
C_{t}^{j} \equiv\left[\int_{0}^{1} c_{t}^{j}(z)^{\frac{\theta-1}{\theta}} d z\right]^{\frac{\theta}{\theta-1}},
$$

where $c_{t}^{j}(z)$ indicates household $j$ 's consumption of good $z$ in period $t$, and $\theta>1$ is the (constant) elasticity of substitution among alternative goods. Similarly, $G_{t}$ is an index of public goods provision in period $t$. The additive way in which $G_{t}$ enters (1.1) implies that public goods are a perfect substitute for private consumption. This is obviously a special case, but has the advantage of allowing us to abstract from any effects of fiscal policy upon the economy other than those that follow from its effect upon the path of the public debt. Finally, $M_{t}^{j}$ denotes the household's money balances at the end of period $t$, while $P_{t}$ is an index of goods prices at date $t$ defined by

$$
P_{t} \equiv\left[\int_{0}^{1} p_{t}(z)^{1-\theta} d z\right]^{\frac{1}{1-\theta}}
$$

where $p_{t}(z)$ is the price of good $z$ at date $t$. This price index has the property that the minimum expenditure required to purchase goods resulting in a consumption index of $C_{t}^{j}$ is given by $P_{t} C_{t}^{j}$. The $v$ term in (1.1) indicates the existence of liquidity services from wealth held in the form of money, increasing in the real purchasing power of the money, as in the model of Sidrauski (1967) and Brock (1974).

Let us suppose that households can trade each period in a range of securities that is large enough to completely span all states of nature. (In particular, it allows households to insure against idiosyncratic variations in the time at which they are able to change the prices at which they supply goods, which is the only householdspecific type of uncertainty in the model.) Then in any period $t$, the flow budget constraint of household $j$ may be written

$$
\begin{gathered}
\int_{0}^{1} p_{t}(z) c_{t}^{j}(z) d z+M_{t}^{j}+E_{t}\left[R_{t, t+1} B_{t+1}^{j}\right] \\
\leq \quad W_{t}^{j}+p_{t}(j) y_{t}(j)-T_{t} .
\end{gathered}
$$

In the final term on the left-hand side, $B_{t+1}^{j}$ denotes the nominal value at date $t+1$ of the bond portfolio (i.e., the non-monetary part of its financial wealth) that the household holds at the end of period $t . R_{t, T}$ denotes the stochastic discount factor, such that the market price at date $t$ of a portfolio yielding a random nominal value $Q_{T}$ at subsequent date $T$ is given by $E_{t}\left[R_{t, T} Q_{T}\right]$. In order for no arbitrage opportunities to exist, securities prices must be characterizable in terms of such discount factors; and because markets are complete, the household can obtain any random payoff $B_{t+1}^{j}$ that it likes in the following period, at a current price of $E_{t}\left[R_{t, t+1} B_{t+1}^{j}\right]$. On the righthand side of (1.4), $W_{t}^{j}$ denotes the nominal value of the household's financial wealth at the beginning of period $t$, given by

$$
W_{t}^{j}=M_{t-1}^{j}+B_{t}^{j} .
$$


Finally, $T_{t}$ denotes net nominal tax obligations of each household during period $t$. These are assumed to be lump-sum, again so as to eliminate effects of fiscal policy changes other than those that result from changes in budgets.

Let us furthermore assume a limit on borrowing that rules out "Ponzi schemes". 5 In this case, the sequence of flow budget constraints (1.4) are equivalent to the sequence of intertemporal budget constraints

$$
\begin{aligned}
& \sum_{T=t}^{\infty} E_{t}\left\{R_{t, T}\left[\int_{0}^{1} p_{T}(z) c_{T}^{j}(z) d z+\frac{i_{T}}{1+i_{T}} M_{T}^{j}\right]\right\} \\
& \leq \quad \sum_{T=t}^{\infty} E_{t}\left\{R_{t, T}\left[p_{T}(j) y_{T}(j) d z-T_{T}\right]\right\}+W_{t}^{j}
\end{aligned}
$$

looking forward from each date $t$, where $i_{t}$ denotes the nominal interest rate on a riskless one-period nominal bond purchased in period $t$, i.e.,

$$
1+i_{t} \equiv\left[E_{t}\left\{R_{t, t+1}\right\}\right]^{-1} \text {. }
$$

(The second term on the left-hand side of (1.6) represents the interest lost each period as the cost of holding some of the household's wealth in non-interest-earning assets.)

Let us now define a monopolistically competitive equilibrium for an economy made up of households of the sort just described. It is clear that an optimizing household allocates its consumption spending across alternative differentiated goods at date $t$ so as to minimize the total expenditure required to achieve a given value of the index $C_{t}^{j}$. Given (1.2), expenditure minimization requires that

$$
c_{t}^{j}(z)=C_{t}^{j}\left(\frac{p_{t}(z)}{P_{t}}\right)^{-\theta}
$$

for each good $z$. (It will be observed that the required minimum expenditure is just $P_{t} C_{t}^{j}$, where $P_{t}$ is the index defined in (1.3).) Let us suppose furthermore that the government has a constant-elasticity- of-substitution production function of the form (1.2) for the supply of public goods; then if the government also allocates its expenditure so as to minimize the cost of producing a supply of public goods $G_{t}$, it will allocate its expenditure in the same proportions as do consumers. It follows that total demand for a good $j$ is given by

$$
y_{t}(j)=Y_{t}\left(\frac{p_{t}(j)}{P_{t}}\right)^{-\theta}
$$

where

$$
Y_{t}=C_{t}+G_{t},
$$

\footnotetext{
${ }^{5}$ See Woodford (1994) for discussion of the type of borrowing limit that will work, and of the equivalence between the flow and intertemporal budget constraints in the presence of such a limit.
} 
and $C_{t} \equiv \int_{0}^{1} C_{t}^{h} d h$ is an index of aggregate demand at date $t$.

We suppose that the household makes its own pricing and spending decisions taking as given those of the other households. Because its own prices and goods demands make only a negligible contribution to the indices $P_{t}$ and $Y_{t}$ respectively, it therefore treats the paths of these two variables as given in making its own decisions. Hence, in deciding upon the price to set for each of its own goods $(j, z)$, it takes as given that its sales each period will depend upon the price charged in the way indicated by (1.8), where $P_{t}$ and $Y_{t}$ are parameters that it cannot affect through its own decisions. Given a specification of monetary and fiscal policy, a rational expectations equilibrium with monopolistic competition is then a specification of stochastic processes such that each household chooses the prices for the goods that it supplies, its consumption spending, and its portfolio of money and other assets, so as to solve the maximization problem just stated, given the evolution of $\left\{P_{t}, Y_{t}, T_{t}\right\}$ and the rates of return on financial assets; such that the indices $\left\{P_{t}, Y_{t}\right\}$ are determined by (1.3) and (1.9), given individual households' decisions; and such that the net demand for all financial assets, including money, by private households equals the supply of such assets by the government. ${ }^{6}$ We proceed to derive a set of equilibrium conditions that characterize such an equilibrium.

Note that because households have identical preferences, and because complete contingent claims markets are assumed to exist, if households start with identical initial wealth, they will choose to completely pool their idiosyncratic income risk (due to setting prices at different dates), maintaining identical wealth levels at all times, and choosing identical consumption plans and money balances. The sense in which we assume identical initial wealth levels is not that $W_{0}^{j}$ is the same for all $j$, but rather that the entire right-hand side of (1.6) has an identical value for each $j$. (Households with a lower present value of expected revenues, because of initial goods prices $p_{-1}(j)$ that are farther from being optimal, are assumed to have a larger value of $W_{0}^{j}$ to compensate for this - exactly because they had insured themselves against that misfortune.) Because it simplifies the characterization of equilibrium, we assume symmetric initial conditions of that kind. Equilibrium then involves identical values of $C_{t}^{j}, M_{t}^{j}$, and so on for all $j$; and so we drop the superscript $j$ in referring to these variables from now on.

Under standard boundary assumptions on household preferences, necessary and sufficient conditions for an optimal consumption and portfolio plan for the representative household are (i) that

$$
\beta^{T-t} \frac{u^{\prime}\left(Y_{T}\right)}{u^{\prime}\left(Y_{t}\right)} \frac{P_{t}}{P_{T}}=R_{t, T}
$$

\footnotetext{
${ }^{6}$ This combination of market power with non-strategic behavior represents the sense in which the equilibrium is "monopolistically competitive".
} 
for any date $t$ and any subsequent date $T$; (ii) that

$$
\frac{v^{\prime}\left(M_{t} / P_{t}\right)}{u^{\prime}\left(Y_{t}\right)}=\frac{i_{t}}{1+i_{t}}
$$

at each date $t$; and (iii) that the intertemporal budget constraint (1.6) for date 0 holds with equality. In writing the household's first-order conditions in the forms (1.10) (1.11), I have used (1.9). Note also that (1.10) implies that the short-term riskless interest rate $i_{t}$ must satisfy

$$
\beta E_{t}\left[\frac{u^{\prime}\left(Y_{t+1}\right)}{u^{\prime}\left(Y_{t}\right)} \frac{P_{t}}{P_{t+1}}\right]=\left(1+i_{t}\right)^{-1}
$$

Finally, it can be shown that condition (iii) implies that (1.6) must similarly hold with equality at each date $t$. Because of complete risk-pooling, the right-hand side of (1.6) for each household takes the same value, which must equal the integral over all households $j$ of the expression given in (1.6). Thus one must have

$$
\sum_{T=t}^{\infty} E_{t}\left\{R_{t, T}\left[P_{T} C_{T}+\frac{i_{T}}{1+i_{T}} M_{T}\right]\right\}=\sum_{T=t}^{\infty} E_{t}\left\{R_{t, T}\left[P_{T} Y_{T}-T_{T}\right]\right\}+M_{t-1}+B_{t}
$$

where now $M_{t}$ denotes the money supply at the end of period $t$, and $B_{t}$ the nominal value of net government debt at the beginning of period $t$. Given that net government debt evolves in accordance with the flow budget constraint for the government,

$$
E_{t}\left[R_{t, t+1} B_{t+1}\right]=B_{t}+P_{t} \Delta_{t}-\left(M_{t}-M_{t-1}\right)
$$

for each $t \geq 0$, where $\Delta_{t} \equiv G_{t}-\left(T_{t} / P_{t}\right)$ is the real primary deficit, condition (1.13) is equivalent to the transversality condition

$$
\lim _{T \rightarrow \infty} E_{t}\left[R_{t, T} W_{T}\right]=0
$$

Next, let us consider the household's optimal pricing decisions, in its capacity as supplier of certain of the differentiated goods. Recall that the household expects to sell a quantity of each good each period given by (1.8). Now suppose that the household is able to set a new price for its good at date $t$. The price applies in period $t$ with certainty, in period $t+1$ with probability $\alpha$, in period $t+2$ with probability $\alpha^{2}$, and so on. This price $p$ is therefore chosen to maximize

$$
\sum_{k=0}^{\infty} \alpha^{k}\left\{\Lambda_{t} E_{t}\left[R_{t, t+k} p y_{t+k}(p)\right]-\beta^{k} E_{t}\left[w\left(y_{t+k}(p)\right)\right]\right\}
$$

where $y_{T}(p)$ denotes the demand at date $T$ indicated by (1.8), and $\Lambda_{t}$ denotes the marginal utility for the household of additional money income at date $t$. (Because the revenues from the sale of an individual good $z$ make only an infinitesimal contribution 
to the household's total intertemporal budget constraint (1.7), one can treat $\Lambda_{t}$ as a constant for purposes of this decision.)

The optimal choice $\mathcal{P}_{t}$ satisfies the first-order condition

$$
\sum_{k=0}^{\infty} \alpha^{k} E_{t}\left\{R_{t, t+k} Y_{t+k}\left(\mathcal{P}_{t} / P_{t+k}\right)^{-\theta}\left[\mathcal{P}_{t}-\mu S_{t+k, t}\right]\right\}=0
$$

where $\mu \equiv \frac{\theta}{\theta-1}>1$ is the factor by which price exceeds marginal revenue as a result of the household's market power, and $S_{T, t}$ denotes the marginal cost of production at date $T$ of a good the price of which was set at $t$, given by

$$
S_{T, t}=\frac{w^{\prime}\left(Y_{T}\left(\mathcal{P}_{t} / P_{T}\right)^{-\theta}\right)}{u^{\prime}\left(Y_{T}\right)} P_{T}
$$

Note that condition (1.16) says, in effect, that the price $\mathcal{P}_{t}$ is given by a desired markup $\mu$ times a weighted average, over future dates and states in which the price may still apply, of the household's expected marginal cost of supplying its good. One observes that the optimal price $\mathcal{P}_{t}$ is the same for all goods the prices of which are changed at date $t$. Equation (1.3) then implies that the price index $\left\{P_{t}\right\}$ evolves according to

$$
P_{t}=\left[\alpha P_{t-1}^{1-\theta}+(1-\alpha) \mathcal{P}_{t}^{1-\theta}\right]^{\frac{1}{1-\theta}} .
$$

This completes the set of conditions that must be satisfied by a rational expectations equilibrium. Equations (1.9) - (1.13) constitute the "aggregate demand block" of the model. These equations determine the evolution of asset holdings, private consumption demand, aggregate demand, and rates of return, given a path for prices $\left\{P_{t}\right\}$ and monetary and fiscal policy. (In the case of a flexible-price Sidrauski-Brock model, as treated in Woodford (1995), these equations determine the equilibrium price level $\left\{P_{t}\right\}$, given an exogenous specification of aggregate supply $\left\{Y_{t}\right\}$; but here it is most useful to think of them as determining aggregate demand $\left\{Y_{t}\right\}$ given the path of prices.) Equivalently, the aggregate demand block may be given by equations $(1.9)-(1.12)$ and $(1.14)-(1.15)$.

Equations (1.16) - (1.18) then comprise the "aggregate supply block" of the model. These equations determine the evolution of marginal costs, new prices $\left\{\mathcal{P}_{t}\right\}$, and the price index $\left\{P_{t}\right\}$, given the variation in aggregate demand. Note that in the flexibleprice limit (the case $\alpha=0$ ), (1.16) becomes simply $\mathcal{P}_{t}=\mu S_{t, t}$, and (1.18) simply $P_{t}=\mathcal{P}_{t}$. Hence in this case, equilibrium requires that $Y_{t}=Y^{*}$ for all $t$, where $Y^{*}$ is the solution to

$$
u^{\prime}\left(Y^{*}\right)=\mu w^{\prime}\left(Y^{*}\right)
$$

regardless of the path of prices. But when $\alpha>0$, it is possible for output to deviate from its "potential" level $Y^{*}$; this, however, must be associated with a discrepancy between $\mathcal{P}_{t}$ and $P_{t}$, and hence with prices changing over time.

These two groups of equations comprise a complete general equilibrium model. We turn now to the effects of fiscal policy upon macroeconomic equilibrium. 


\section{Fiscal Policy as a Source of Macroeconomic In- stability}

In order to illustrate how, in the absence of any constraints upon fiscal policy, stochastic variation in the government's budget can interfere both with price stability and with macroeconomic stability more generally, even under such ultra-Ricardian assumptions as have been made above, I shall here restrict attention to a simple case. This is the case in which the real primary deficit $\left\{\Delta_{t}\right\}$ follows an exogenous stochastic process; neither the accumulated level of the public debt, nor other variables such as the rate of inflation or the level of interest rates, have any effect upon it. Under this assumption, one can show not only that innovations in the deficit process may disturb the paths of inflation, interest rates, and output. Rather, one can show that in the case of almost any such process, fiscal disturbances must have such an effect, regardless of the nature of monetary policy.

This is easily shown by contradiction. Suppose that a monetary policy rule exists which results in stable prices, despite exogenous fluctuations in the government budget. Because of (1.18), an equilibrium with stable prices would have to involve $\mathcal{P}_{t}=P_{t}$ at all times. It then follows that substitution of (1.10) and (1.17) into (1.16) yields an equilibrium condition of the form

$$
\Phi_{t} \equiv \sum_{k=0}^{\infty} \alpha^{k} E_{t}\left[\theta\left(Y_{t+k}\right)\right]=0
$$

where

$$
\theta(Y) \equiv Y\left[u^{\prime}(Y)-\mu w^{\prime}(Y)\right]
$$

Now it follows from the definition of $\Phi_{t}$ that

$$
\Phi_{t}=\theta\left(Y_{t}\right)+\alpha E_{t} \Phi_{t+1}
$$

hence (2.1) implies that $\theta\left(Y_{t}\right)=0$ at all times. It is easily seen that this requires that $Y_{t}=Y^{*}$ at all times, where $Y^{*}$ is defined by (1.19). It then follows from (1.12) that $i_{t}$ is constant at all times, and from (1.11) that $M_{t}$ is constant at all times as well.

Substituting these constant values, together with (1.9) - (1.10), into (1.13), the latter equilibrium condition reduces to

$$
m^{*}-\delta_{t}=W_{t} / P^{*}
$$

where $P^{*}$ is the constant price level, $m^{*}$ is the constant level of real money balances satisfying (1.11), $W_{t}$ is the beginning-of-period financial wealth defined by (1.5), and

$$
\delta_{t} \equiv \sum_{j=0}^{\infty} \beta^{j} E_{t} \Delta_{t+j}
$$


measures the present value of current and future primary deficits, using the discount factors (1.10) associated with such an equilibrium. But note that $W_{t}$ is a predetermined state variable. If the government issues only riskless one-period nominal bonds (as assumed in the simulations below), then $B_{t}$ (the nominal value at the beginning of period $t$ of bonds issued in period $t-1$ ) is a predetermined variable, and so is $W_{t}$. But even if the government issues indexed debt or long-term debt, the market value of such debt at the beginning of period $t$ cannot depend upon any fiscal innovation at date $t$, given that (by hypothesis) the price level never changes and (by implication) the discount factors $\left\{R_{t, T}\right\}$ never change. ${ }^{7}$ It then follows from (2.2) that a fiscal shock at date $t$ can never change the expected value of the present value of future government budget deficits, $\delta_{t}$, either. Thus a fiscal policy that implies random variations in that variable (as in the case of most exogenous stochastic processes $\left\{\Delta_{t}\right\}$ ) is necessarily inconsistent with price stability, regardless of the form of the monetary policy rule. ${ }^{8}$

Now it might be supposed that this inconsistency with a zero-inflation equilibrium reflects the fact that such a fiscal policy is inconsistent with any rational expectations equilibrium - in other words, it might be supposed that I have postulated an "unsustainable" fiscal policy. But this is not so, or at any rate not necessarily; for many specifications of monetary policy, the assumption of an exogenous primary deficit is consistent with equilibrium, though the resulting equilibrium necessarily does not involve stable prices. To illustrate this possibility, I further specify the policy regime. First, I shall assume that monetary policy is formulated in terms of a feedback rule for short-term nominal interest rates, of the form

$$
i_{t}=\Phi\left(\pi_{t}, Y_{t}\right) \text {, }
$$

where $\pi_{t} \equiv P_{t} / P_{t-1}$ measures the rate of inflation, and $Y_{t}$ is the index of aggregate activity defined in (1.9). ${ }^{9}$ Note that this represents an autonomous monetary policy, in the sense that the central bank's choice of its policy instrument is not conditioned upon the size of the public debt, or any other fiscal variables; the central bank responds only to changes in the rate of inflation, and to the level of real activity (which it may care about, if only because this indicates inflationary pressure because of (1.16) - (1.17)). Thus the effects of fiscal shocks demonstrated below do not result from any intention of the central bank to "monetize" the public debt, or to meet a seignorage target that varies with the government's budget deficit. Second, I shall assume that the government issues only riskless, one-period nominal debt. As a result, $B_{t}$ is a

\footnotetext{
${ }^{7}$ Here it is assumed, of course, that the amount that the governmment commits itself to pay on its debt is not itself contingent upon subsequent fiscal shocks.

${ }^{8}$ One can think of non-trivial stochastic processes for which $\delta_{t}$ never varies, such as $\Delta_{t}=\epsilon_{t}-$ $\beta^{-1} \epsilon_{t-1}$, for $\left\{\epsilon_{t}\right\}$ another stationary stochastic process. But these are extremely special cases.

${ }^{9}$ Many central banks appear to implicitly determine their policies according to an interest rate rule of this general type; see, e.g., Taylor (1993), Clarida and Gertler (1995).
} 
predetermined state variable at date $t$, that evolves according to the law of motion

$$
B_{t+1}=\left(1+i_{t}\right)\left[B_{t}+P_{t} \Delta_{t}-\left(M_{t}-M_{t-1}\right)\right]
$$

given the initial conditions $B_{0}$ and $M_{-1}$. (This is simply the form taken by (1.14) under this particular assumption about the nature of government debt.) Neither of these special assumptions is necessary in order for the exogenous deficit policy to be sustainable; but some assumptions must be made in order to compute the equilibrium, and these are intended to be relatively realistic for advanced industrial nations with low average rates of inflation.

To demonstrate the consistency of such a policy mix with rational expectations equilibrium, it suffices to consider equilibria in which all state variables follow paths that are close to the values they would have in a stationary deterministic equilibrium. Such equilibria can exist in the case of stochastic disturbances (in the present case, stochastic variation in the government budget), if these disturbances are small enough; we shall restrict attention here to that case. In order to characterize equilibria of this kind, it suffices to consider a linearization of the system of equilibrium conditions set out in section 1, with the linearization performed around the stationary values of the state variables that represent an equilibrium in the absence of disturbances.

Let us suppose that "the absence of disturbances" means some constant level of real primary deficit $\Delta^{*}$, and. a deterministic feedback rule of the form (2.4) for monetary policy. Let us suppose furthermore that the rule (2.4) is such that (i) $\Phi\left(1, Y^{*}\right)=\beta^{-1}-1$, and that (ii) $\Delta^{*}<0$ (i.e., there is a constant primary surplus in the absence of disturbances). These conditions are necessary for the policy regime in the absence of disturbances to be consistent with complete price stability (zero inflation with certainty), assuming that the initial government debt $B_{0}$ is positive. Given them, one can show that such a stationary equilibrium exists, with a constant level of output $Y^{*}$ (defined in (1.19)) of all goods, and a constant nominal interest rate of $i^{*}=\beta^{-1}-1$.

Under this specification of policy, the aggregate demand block of the model reduces to the system of equations (1.11) $-(1.12)$ and (2.4) $-(2.5)$ each period, to be solved for the paths of $\left\{Y_{t}, i_{t}, M_{t}, B_{t+1}\right\}$ from period $t=0$ onward, given the path of $\left\{P_{t}\right\}$, the exogenous process $\left\{\Delta_{t}\right\}$, and the initial conditions $B_{0}, M_{-1}, P_{-1}$. ${ }^{10}$ We may linearize these equations in terms of the deviations of the variables $m_{t}\left[\equiv M_{t} / P_{t}\right]$, $Y_{t}, i_{t}, \pi_{t}, \Delta_{t}$, and $b_{t}\left[\equiv B_{t} / P_{t-1}\right]$, from their stationary values, denoted $m^{*}, Y^{*}$, and so on. It is useful to write the equations in terms of "deflated" variables such as $m_{t}$ and $b_{t}$ because no equilibrium conditions actually involve the absolute levels of nominal variables, as opposed to their ratios. And as we shall see, there very generally exists an equilibrium in which the "deflated" variables, including $\pi_{t}$, vary only a small amount around their stationary values, while the price level (and, correspondingly,

\footnotetext{
${ }^{10}$ Note that we may ignore condition (1.15), as we are in any event considering only solutions in which interest rates, inflation, and real financial wealth remain forever near their stationary equilibrium paths, in any of which (1.15) will necessarily be satisfied.
} 
other nominal quantities) may eventually drift far from any given value (following a random walk with small conditional variance over any short horizon, but large variance over long enough horizons). The value of government debt is deflated by the previous period's price level so that $b_{t}$, like $B_{t}$, is a predetermined state variable at date $t$.

The linearized aggregate demand block is given by ${ }^{11}$

$$
\begin{gathered}
\hat{m}_{t}=\chi\left[\sigma^{-1} \hat{Y}_{t}-(\beta / 1-\beta) \hat{i}_{t}\right], \\
\hat{Y}_{t}=E_{t} \hat{Y}_{t+1}-\sigma\left(\hat{i}_{t}-E_{t} \hat{\pi}_{t+1}\right), \\
\hat{i}_{t}=\phi_{\pi} \hat{\pi}_{t}+\phi_{y} \hat{Y}_{t}
\end{gathered}
$$

and

$$
\hat{b}_{t+1}=\hat{i}_{t}+\beta^{-1}\left(\hat{b}_{t}-\hat{\pi}_{t}\right)+\left(\beta^{-1}-1\right) \hat{\Delta}_{t}+\gamma\left(\hat{m}_{t-1}-\hat{m}_{t}-\hat{\pi}_{t}\right)
$$

where $\hat{m}_{t}, \hat{Y}_{t}, \hat{i}_{t}, \hat{\pi}_{t}, \hat{b}_{t}$ denote percentage deviations of $m_{t}, Y_{t}, 1+i_{t}, \pi_{t}$, and $b_{t}$ respectively from their stationary values, and $\hat{\Delta}_{t} \equiv\left(\Delta^{*}-\Delta_{t}\right) / \Delta^{*}$. (The alternative definition for $\hat{\Delta}_{t}$ is used so that $\hat{\Delta}_{t}$ has the same sign as $\Delta_{t}$, and so that $\hat{\Delta}_{t}$ is defined even if the sign of $\Delta_{t}$ is not the same as that of $\Delta^{*}$.) The coefficients of these equations are written in terms of the preference parameters 12

$$
\sigma \equiv-\frac{u^{\prime}\left(Y^{*}\right)}{u^{\prime \prime}\left(Y^{*}\right) Y^{*}}, \quad \chi \equiv-\frac{v^{\prime}\left(m^{*}\right)}{v^{\prime \prime}\left(m^{*}\right) m^{*}},
$$

the monetary policy parameters $\phi_{\pi}, \phi_{y}$, indicating the elasticities of $\Phi$ with respect to its two arguments, and the parameter

$$
\gamma \equiv \frac{m^{*}}{\beta b^{*}}
$$

indicating the relative importance of money and bonds in overall financial wealth.

One may similarly linearize the aggregate supply block of the model, equations (1.16) - (1.18), obtaining

$$
\begin{gathered}
\hat{\mathcal{P}}_{t}=(1-\alpha \beta) \sum_{k=0}^{\infty}(\alpha \beta)^{k} E_{t}\left\{\hat{s}_{t+k, t}+\sum_{s=t+1}^{t+k} \hat{\pi}_{s}\right\} \\
\hat{s}_{T, t}=\left(\omega^{-1}+\sigma^{-1}\right) \hat{Y}_{t}-\theta / \omega\left[\hat{\mathcal{P}}_{t}-\sum_{s=t+1}^{T} \hat{\pi}_{s}\right]
\end{gathered}
$$

and

$$
\hat{\pi}_{t}=\frac{1-\alpha}{\alpha} \hat{\mathcal{P}}_{t}
$$

\footnotetext{
${ }^{11}$ These equations represent linearizations of (1.11), (1.12), (2.4), and (2.5) respectively.

${ }^{12}$ The parameter $\sigma$ measures the elasticity of substitution between consumption at different dates; $\chi$ measures the elasticity of the demand for money with respect to the "cost" $i_{t} / 1+i_{t}$ of holding money balances.
} 
where $\hat{\mathcal{P}}_{t}$ denotes the percentage deviation of $\mathcal{P}_{t} / P_{t}$ from its stationary value (one), and $\hat{s}_{T, t}$ denotes the percentage deviation of $S_{T, t} / P_{T}$ from its stationary value $(1 / \mu)$. In (2.11), use is made of the additional preference parameter ${ }^{13}$

$$
\omega \equiv \frac{w^{\prime}\left(Y^{*}\right)}{w^{\prime \prime}\left(Y^{*}\right) Y^{*}} .
$$

These equations may be reduced to a single "aggregate supply curve" as follows. Substituting (2.11) into (2.10) and rearranging terms, one obtains

$$
\hat{\mathcal{P}}_{t}=\frac{\kappa \alpha}{1-\alpha} \sum_{k=0}^{\infty}(\alpha \beta)^{k} E_{t} \hat{Y}_{t+k}+\sum_{k=1}^{\infty}(\alpha \beta)^{k} E_{t} \hat{\pi}_{t+k}
$$

where

$$
\kappa \equiv \frac{(1-\alpha)(1-\alpha \beta)}{\alpha \cdot} \frac{\omega+\sigma}{\sigma(\omega+\theta)} .
$$

This may equivalently be expressed in the quasi-differenced form ${ }^{14}$

$$
\hat{\mathcal{P}}_{t}=\alpha \beta E_{t} \hat{\mathcal{P}}_{t+1}+\frac{\kappa \alpha}{1-\alpha} \hat{Y}_{t}+\alpha \beta E_{t} \hat{\pi}_{t+1}
$$

Substituting (2.12) into (2.13) in order to eliminate the variable $\left\{\hat{\mathcal{P}}_{t}\right\}$, one finally obtains

$$
\hat{\pi}_{t}=\beta E_{t} \hat{\pi}_{t+1}+\kappa \hat{Y}_{t}
$$

as an equation to determine the equilibrium path of inflation associated with a given path of deviations $\left\{\hat{Y}_{t}\right\}$ of output from potential output $Y^{*}$. Note that equation $(2.14)$ represents a form of expectations-augmented "Phillips curve". ${ }^{15}$

Our complete equation system then consists of equations (2.6) - (2.9) and (2.14), to be solved for the paths of $\left\{\hat{m}_{t}, \hat{Y}_{t}, \hat{i}_{t}, \hat{\pi}_{t}, \hat{b}_{t}\right\}$ given an exogenous process for $\left\{\hat{\Delta}_{t}\right\}$ and initial conditions $\hat{b}_{0}$ and $\hat{m}_{-1}$. In considering the solution of this system, it is useful to rewrite $(2.9)$ as

$$
\hat{b}_{t+1}+E_{t} \delta_{t+1}=\hat{i}_{t}+\beta^{-1}\left(\hat{b}_{t}+\hat{\delta}_{t}-\hat{\pi}_{t}\right)+\gamma\left(\hat{m}_{t-1}-\hat{m}_{t}-\hat{\pi}_{t}\right)
$$

where

$$
\hat{\delta}_{t} \equiv(1-\beta) \sum_{j=0}^{\infty} \beta^{j} E_{t} \hat{\Delta}_{t+j}
$$

measures the percentage deviation of the variable $\delta_{t}$ defined in (2.3) from its steadystate value. It is also useful to eliminate the state variable $\hat{i}_{t}$ by substituting (2.8)

\footnotetext{
${ }^{13}$ The parameter $\omega$ indicates what the elasticity of supply of a price-taking household would be to a change in the price at which it could sell one of the goods that it produces.

${ }^{14}$ The two forms are equivalent given that we care only about bounded solutions, and given that $|\alpha \beta|<1$.

${ }^{15}$ See Roberts (1995) for econometric support for this specification in the case of the U.S. economy.
} 
into the other equations. The resulting system of four stochastic difference equations can be written in vector form as

$$
E_{t} x_{t+1}=M x_{t}
$$

where the vector of state variables $x_{t}$ is the transpose of

$$
x_{t}^{\prime} \equiv\left[\begin{array}{llll}
\hat{\pi}_{t} & \hat{Y}_{t} & \hat{m}_{t-1} & \hat{b}_{t}+\hat{\delta}_{t}
\end{array}\right]
$$

and $\mathrm{M}$ is a $4 \times 4$ matrix of coefficients. In rewriting the equations in this form, it is to be understood that $E_{t} \hat{m}_{t}=\hat{m}_{t}$, and $E_{t} \hat{b}_{t+1}=\hat{b}_{t+1}$.

As usual, the existence or not of a unique bounded solution for the vector of state variables $\left\{x_{t}\right\}$, given an arbitary bounded forcing process $\left\{\hat{\Delta}_{t}\right\}$, depends upon the number of eigenvalues of the matrix $M$ that lie inside the unit circle (see, e.g., Blanchard and Kahn, 1980). Specifically, since there are two predetermined state variables, local determinacy of the rational expectations equilibrium depends upon their being exactly two such eigenvalues. ${ }^{16}$ Note that $M$ may be written in block form as ${ }^{17}$

$$
M=\left(\begin{array}{cc}
A & 0 \\
C & D
\end{array}\right),
$$

where each block is $2 \times 2$. Because of the block triangularity, the eigenvalues of $M$ are just the two eigenvalues of $A$ and the two eigenvalues of $D$. Since

$$
D=\left(\begin{array}{ll}
0 & 0 \\
\gamma & \beta^{-1}
\end{array}\right)
$$

two of the eigenvalues are 0 and $\beta^{-1}$, and since $0<\beta<1$, only the first of these lies inside the unit circle. Thus determinacy requires that the block $A$ have one stable and one unstable eigenvalue as well. It can be shown that this condition is satisfied if and only if ${ }^{18}$

$$
-1-\frac{1+\beta}{\kappa} \phi_{y}-\frac{2(1+\beta)}{\kappa \sigma}<\phi_{\pi}<1-\frac{1-\beta}{\kappa} \phi_{y}
$$

\footnotetext{
${ }^{16}$ Technically, this result depends upon certain generically valid regularity conditions, that I do not further discuss here. Numerical solution of the model indicates that these conditions are typically satisfied in the present case. For discussion of a general approach to solution of a broader class of models, see King and Watson (1995).

${ }^{17}$ In this form, the four rows of the vector of equations correspond to equations $(2.14),(2.7),(2.6)$, and (2.9) respectively. Equation (2.8) is first substituted into the last three equations to eliminate the interest rate, and equation (2.14) is substituted into (2.7) to eliminate $E_{t} \hat{\pi}_{t+1}$ from the second equation.

${ }^{18}$ Note that in the flexible-price limit $(\kappa \rightarrow \infty)$, these conditions come to coincide with those found by Leeper (1991), i.e., that $\left|\phi_{\pi}\right|<1$. Leeper calls monetary policies satisfying this requirement "passive". This condition is required for existence of a bounded solution because, in Leeper's terminology, our assumption of an exogenous process for the primary deficit is an example of an "active" fiscal policy.
} 
Note that a pure interest rate peg $\left(\phi_{\pi}=\phi_{y}=0\right)$ satisfies these requirements, as will any policy of the form (2.4) that involves sufficiently moderate responses of nominal interest rates to changes in the rate of inflation and economic activity.

If the monetary policy rule satisfies conditions (2.17), a unique solution to equations (2.16) can be found, in which bounded fluctutions in the path of the government deficit lead to bounded fluctuations in the other variables. The solution can be written in the form $\hat{\pi}_{t}=\xi_{\pi} z_{t}, \hat{Y}_{t}=\xi_{y} z_{t}$, where

$$
z_{t} \equiv \hat{b}_{t}+\hat{\delta}_{t}+\beta \gamma \hat{m}_{t-1}
$$

with the evolution of the state variable $\left\{z_{t}\right\}$ given by

$$
z_{t+1}=\lambda z_{t}+\left[\hat{\delta}_{t+1}-E_{t} \hat{\delta}_{t+1}\right]
$$

where $\lambda$ is the eigenvalue of $A$ with modulus less than one. These equations describe a unique bounded solution for the variables $\left\{\hat{\pi}_{t}, \hat{Y}_{t}\right\}$, given an exogenous bounded process $\left\{\hat{\delta}_{t}\right\}$. Equations (2.6) and (2.8) - (2.9) then imply unique bounded paths for the variables $\left\{\hat{i}_{t}, \hat{m}_{t}, \hat{b}_{t}\right\}$ as well.

One observes that disturbances to the path of the real primary deficit $\left\{\hat{\Delta}_{t}\right\}$, and hence to the path of the public debt, will in general result in disturbances to the paths of inflation, interest rates, and output. Note, however, that a fiscal shock at date $t$ affects inflation, interest rates or output at that date - or the conditional expectation at date $t$ of future values of any of these variables - only if it changes the expected present value of future government deficits $\hat{\delta}_{t}$. What determines whether a fiscal shock is expansionary or contractionary is the sign of its effect upon $\hat{\delta}_{t}$, rather than its effect upon the current deficit $\hat{\Delta}_{t}$ alone.

The effects of a disturbance to the value of $\hat{\delta}_{t}$ may usefully be illustrated by numerical solution of the model. ${ }^{19}$ In Figures 1 and 2, impulse responses are reported for a $20 \%$ positive innovation in the size of the real primary deficit, under the assumption that the deficit follows an exogenous, stationary first-order autoregressive process

$$
\hat{\Delta}_{t}=\rho \hat{\Delta}_{t-1}+\nu_{t}
$$

where $\left\{\nu_{t}\right\}$ is an i.i.d. random variable with mean zero and bounded support, and $|\rho|<1$. In these simulations, the model parameters are given the values $\beta=.95, \kappa=$ $.3, \sigma=1, \chi=1$, and $\gamma=.1{ }^{20}$ The serial correlation coefficient for the deficit

\footnotetext{
${ }^{19}$ The program of King and Watson (1995) is used in computing the impulse responses reported in Figures 1 and 2.

${ }^{20}$ The value assumed for $\beta$ implies a rate of time preference of $5 \%$ per year, a value that is roughly consistent with observed real rates of return. The value assumed for $\kappa$ is consistent with the econometric estimates of Roberts (1995). The value assumed for $\sigma$ is the one that would result if $u(C)=\log C$, and implies an intertemporal elasticity of substitution of consumption of 1 ; this value is standard in calibrated growth models. The value assumed for $\chi$ is the one that would result if $v(m)=\log m$, and implies an income elasticity of money demand of one; this value is roughly consistent with many studies of money demand, especially ones that emphasize lowfrequency movements in money demand. The value assumed for $\gamma$ is roughly consistent with the relative sizes of the monetary base and the government debt of the U.S.
} 
process is assumed to be $\rho=.6$. In Figure 1, nominal interest rates are assumed not to be adjusted much in response to variations in inflation and economic activity; the parameters of the monetary policy rule (3.4) are assumed to be $\phi_{\pi}=\phi_{y}=.1$.

The six panels of Figure 1 display the impulse responses of real output $\left(\hat{Y}_{t}\right)$, the inflation rate $\left(\hat{\pi}_{t}\right)$, the short-term nominal interest rate $\left(\hat{i}_{t}\right)$, the ex-ante real rate $\left(\hat{i}_{t}-E_{t} \hat{\pi}_{t+1}\right)$, the real government debt $\left(\hat{b}_{t}\right)$, and the real primary deficit $\left(\hat{\Delta}_{t}\right)$. The periods represent years, and zero indexes the year in which the innovation to the deficit process occurs. The lower right panel indicates the exogenous rate of mean reversion assumed for the primary deficit. Because $\left\{\hat{b}_{t}\right\}$ is a predetermined state variable, there is no response of this variable until the following period; the other variables jump immediately when the shock occurs, then return gradually to their steady-state values.

One observes that the unexpected increase in the primary deficit, not offset by any expected reduction in future primary deficits, stimulates aggregate demand, temporarily increasing both inflation and output. This shows that "Ricardian equivalence" does not hold here, despite the assumptions of rational expectations, identical infinite-lived households, pure lump-sum taxation, and frictionless financial markets, and despite the fact that the monetary policy rule (2.4) does not imply any direct dependence of monetary policy upon fiscal variables. The reason why an increase in the present value of government budget deficits (at the prices and interest rates that would otherwise clear markets) increases aggregate demand is simple. An increase in the present value of the government deficit increases the present value of "total consumption" that the representative household can afford, if prices and interest rates do not change, and thus induces an increase in the aggregate demand for goods (at those given prices). ${ }^{21}$ Nor can an increase in output relative to potential, by itself, succeed in restoring equality between demand and supply in the goods market. For increased sales mean increased incomes (as Keynes observed), and so as long as the value of government liabilities exceeds the present value of expected government budget surpluses, households will be able to afford "total consumption" with a present value greater than the present value of the economy's output. Equilibrium therefore requires adjustment of prices and/or interest rates so as to preserve equality between the value of outstanding government liabilities and the present value of future government surpluses (counting seignorage income).

This equality may be restored through adjustments of three sorts. First, due to the endogeneity of the money supply under a policy regime of the kind specified in (2.4), seignorage revenues may increase, as the money supply expands to accommodate the increased demand as a result of inflation. Second, given the existence of nominal government debt, unexpected inflation as a result of the fiscal shock may reduce the

\footnotetext{
${ }^{21}$ The existence of this wealth effect depends upon the fact that the assumed fiscal policy does not have the "Ricardian" property discussed in the next section, and implicitly assumed in the literature on Ricardian equivalence.
} 
Figure 1. $\phi_{\pi}=\phi_{y}=.1$.
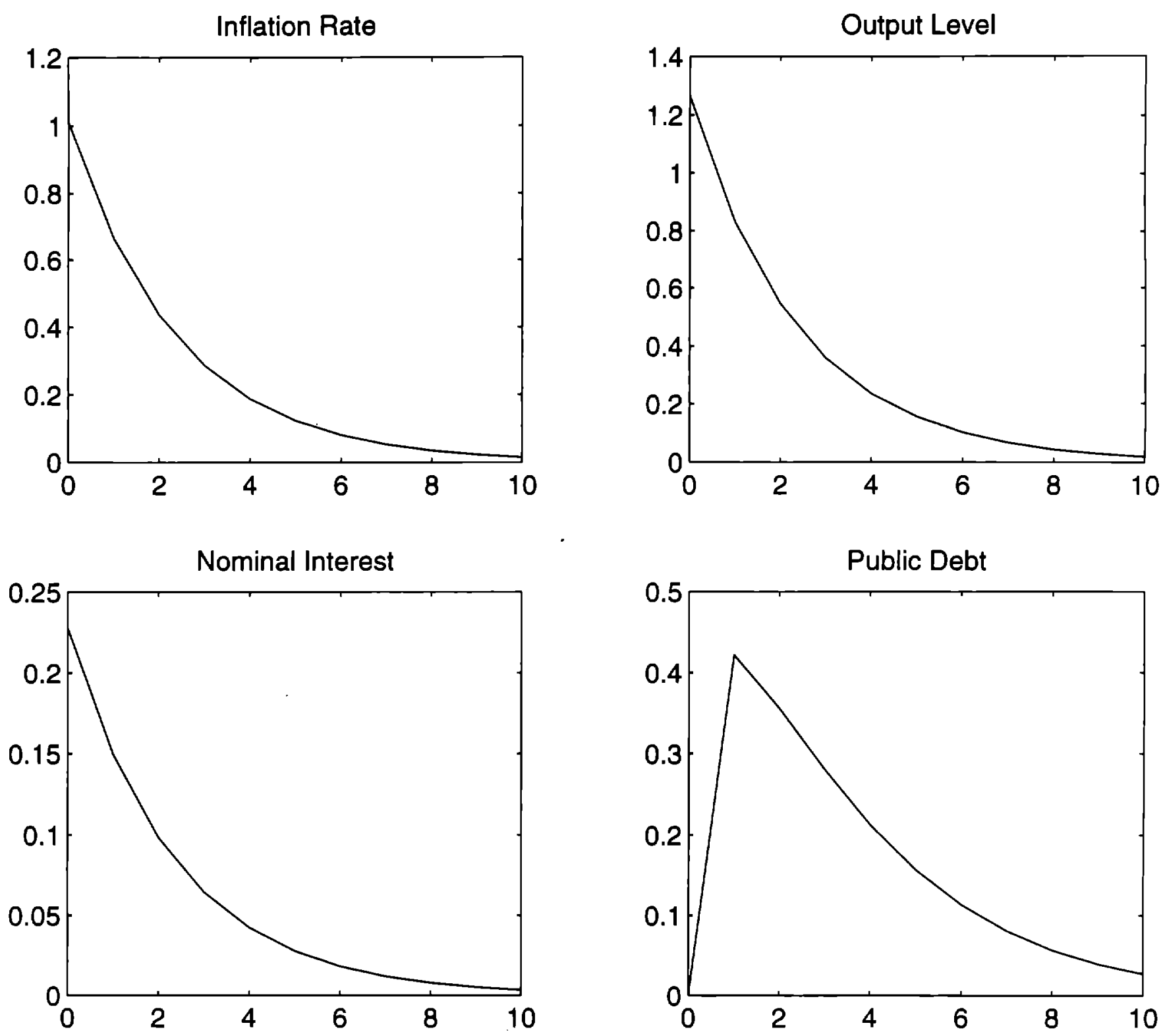

Real Interest
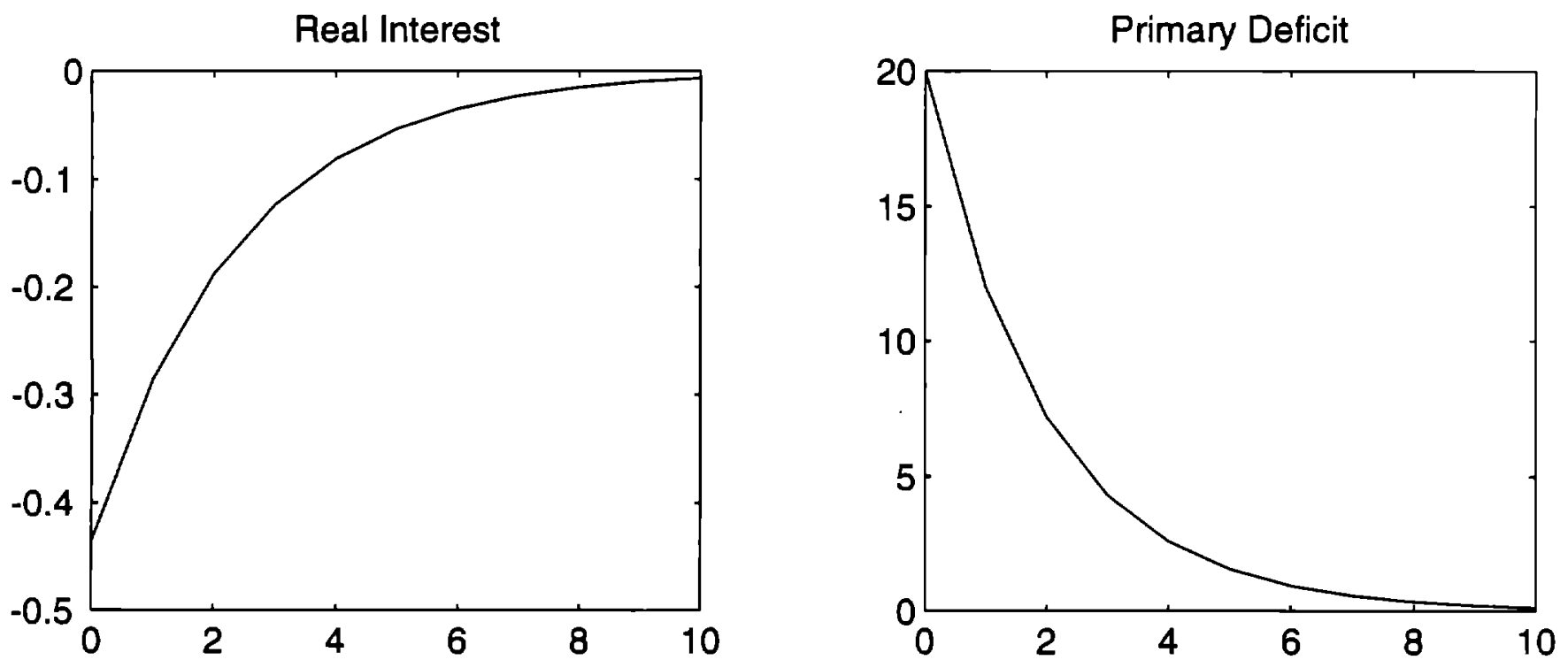
real value of outstanding government liabilities. ${ }^{22}$ And third, a reduction in the real interest rate that must be paid on government debt allows the government to service its debt (even without a drop in its real value) with smaller primary surpluses.

Both increased inflation and lower real interest rates naturally occur in the present model, as a result of the increase in aggregate demand; and the extent to which demand actually increases, in equilibrium, is exactly the extent that suffices to produce a capital loss and a real interest rate decline that suffice to prevent households from being able to afford more goods than the economy supplies. Unexpected inflation occurs as a direct result of increased demand for goods; output above potential implies a "marginal cost" higher than $\mu^{-1}$ times the general price index, so that the prices of goods that are newly set at the time of the shock $\left(\mathcal{P}_{t}\right)$ are set higher than the index of existing prices $\left(P_{t-1}\right)$, resulting in inflation. The monetary policy rule assumed here implies that nominal interest rates are raised as a result of both higher output and inflation; but they are not raised as much as the increase in inflation, and the ex ante real rate declines. This does not require any violation of the equilibrium relation that must exist between the real rate of interest and households' intertemporal marginal rate of substitution. Because of the price adjustment that eventually occurs, output does not remain above potential forever. The fact that it is temporarily high means that real interest rates must fall, so as to induce households to consume a relatively greater amount in the period immediately following the fiscal shock.

In the simulation reported, a $20 \%$ unexpected increase in the primary government budget deficit results in a $1 \%$ increase in inflation (i.e., from zero to $1 \%$ per year), and slightly more than a $1 \%$ increase in real GDP. Nominal interest rates rise by only a little more than 20 basis points, implying a decline in the real rate of more than 40 basis points. The capital loss on existing nominal government liabilities due to the increased inflation is not sufficient to prevent an increase in the real value of outstanding government debt at the beginning of year 1. (Some of the increase in the value of government debt in the hands of the public also comes about due to the sale of government debt by the central bank, in the open market operations through which it raises nominal interest rates.) The real government debt declines back to its steady-state level over the next several years, however, both as a result of increased seignorage revenues, and as a result of the decreased real interest rates at which the government is able to roll over its debt in those years.

Figure 2 shows how the outcome differs if the central bank is more aggressive about increasing nominal interest rates when inflation accelerates. All model parameters are the same as in Figure 1 (including the assumed serial correlation of the deficit process), except that the parameters of the monetary policy rule are now $\phi_{\pi}=.9, \phi_{y}=.5 .{ }^{23}$

\footnotetext{
${ }^{22}$ This is the channel emphasized in the flexible-price model discussed in Woodford (1995); only these first two channels are operative in that model.

${ }^{23}$ These values are close to the upper bound given in (2.17), for existence of an equilibrium in which all state variables remain forever near their steady-state values, so that our linearization technique can be used.
} 
Figure 2. $\phi_{\pi}=.9, \phi_{y}=.5$.
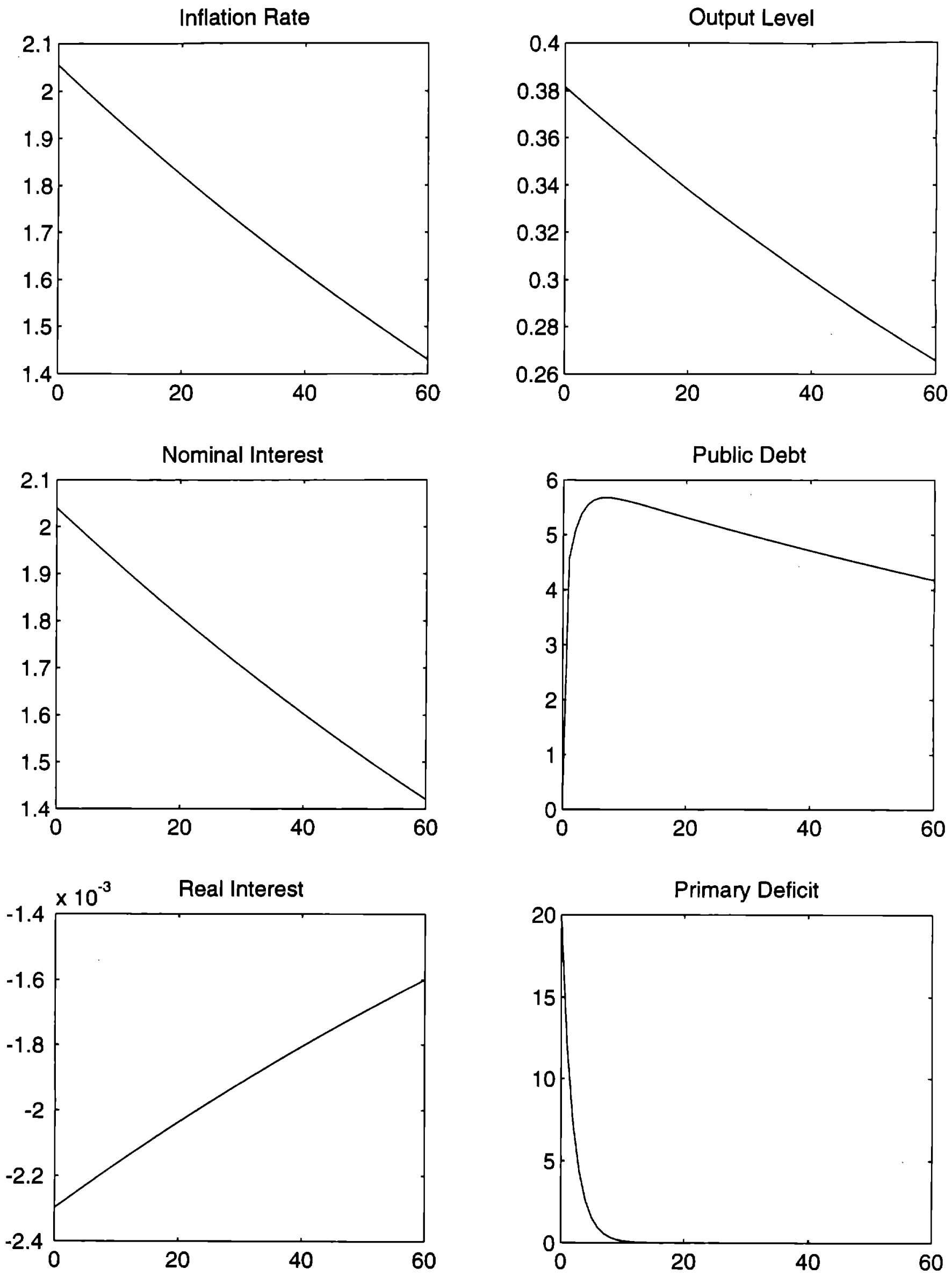
As a result of this kind of monetary policy, the increase in inflation results in only a small decline in the real interest rate on government debt. But the consequence is simply that inflation increases to a greater extent, and that it remains high for a much longer time. The real government debt grows by much more under this policy, because the central bank must sell much more government debt to the public in order to raise interest rates. And because the central bank prevents the real rate of interest from declining much, it takes a very long time for the real government debt to return to its steady state level. (For the period of 60 years plotted in the figure, the debt level remains far from steady state over the entire period.) Thus an attempt on the part of the central bank to keep nominal interest rates more closely aligned with inflation does not prevent a pure fiscal shock from disturbing the paths of inflation, interest rates, and output - in fact, as far as inflation and nominal interest rates are concerned, it greatly increases the volatility of these variables resulting from a given degree of volatility of the fiscal shocks $\left\{\nu_{t}\right\}$.

The finding that an exogenous primary deficit can force an increase in the rate of inflation - and even more, the finding that a less accommodative monetary policy results in more, rather than less, inflation under such circumstances - recalls the much-discussed "unpleasant monetarist arithmetic" of Sargent and Wallace (1981). My argument here is indeed very much in the spirit of theirs. Yet a number of novel features of the analysis are worth emphasizing.

One is that Sargent and Wallace's analysis assumes an upper bound upon the size of the real government debt, presumably to be justified (in terms of the overlapping generations model that they discuss) by the maximum quantity of resources that a young generation can possibly transfer in order to acquire the public debt from its elders. It might then be suspected that their analysis should not apply to an economy in which wealth is passed on to subsequent generations through bequests. But here we obtain similar results for an economy made up of infinite-lived households (which we may understand to represent families made up of successive finite-lived households linked by altruistic bequests, as in the model of Barro, 1974), and no limit upon the size that the public debt may reach is assumed. In fact, as is discussed in the next section, the result that fiscal shocks force the price level to increase actually depends, in a sense, upon the fact that the government is not constrained to keep the level of the public debt within any upper bound - for this is what allows a violation of Ricardian equivalence.

A more important difference is that in Sargent and Wallace's analysis, an exogenous primary deficit causes inflation because the central bank is sooner or later forced to monetize it. Many macroeconomists feel that this scenario is unlikely in a lowinflation country. ${ }^{24}$ First, Sargent and Wallace depict monetary policy as eventually being subordinated to the need to achieve a particular level of real seignorage revenues. But many find it unlikely that this would ever become the main consideration in setting monetary policy in a low-inflation country, given that seignorage revenues

\footnotetext{
${ }^{24}$ King (1995) clearly expresses this common view.
} 
make such a small average contribution to government revenues in such countries. In addition, Sargent and Wallace depict this as coming about because the central bank is constrained to choose a policy that is consistent with the government's fiscal needs, as a result of its being a Stackelberg "follower", or the party that flinches in a "game of chicken" between the monetary and fiscal authorities. This suggests that a sufficiently independent central bank can avoid such consequences, if it credibly commits itself in advance to a monetary policy rule that ignores the size of the public debt, so that it becomes the Stackelberg "leader". ${ }^{25}$

The analysis here shows that the inflationary consequences of an exogenous fiscal policy cannot be so easily dismissed. In the model presented above, the central bank does commit itself in advance to an autonomous monetary policy rule (described by equation (2.4)), and it is never forced to deviate from that policy. The inflationary effects of an increased primary deficit come about, not because the central bank changes its policy, but as a result of the effects of government fiscal policy on private spending decisions (through the wealth effect discussed above). Thus mere confidence in the independence of a country's central bank (or that of the proposed European central bank) or in its single-minded concern with inflation is not sufficient ground to exclude the possibility of inflationary pressures resulting from fiscal policy shocks.

Not only is the central bank's policy not geared to the achievement of a seignorage target in these simulations, but the creation of seignorage revenues is not essential to the mechanism through which inflation restores the equilibrium that is disturbed by an exogenous increase in the primary deficit. Integration of (2.15) forward in time yields

$$
\hat{\delta}_{t}=-\left(\hat{b}_{t}-\hat{\pi}_{t}\right)+\gamma \sum_{j=0}^{\infty} \beta^{j+1} E_{t}\left[\hat{\mu}_{t+j}\right]-\sum_{j=0}^{\infty} \beta^{j+1} E_{t}\left[\hat{i}_{t+j}-\hat{\pi}_{t+j+1}\right],
$$

where $\hat{\mu}_{t} \equiv \hat{m}_{t}-\hat{m}_{t-1}+\hat{\pi}_{t}$ denotes the percentage deviation in the rate of growth of the nominal money supply $\left(M_{t} / M_{t-1}\right)$. Fiscal shocks that change the present value of government budget deficits (at what would otherwise be the equilibrium rates of return) - i.e., that perturb $\hat{\delta}_{t}$ - are possible in equilibrium, because of the possibility of simultaneous adjustment of each of the three terms on the right-hand side of (2.18). These three terms correspond to the three channels of adjustment discussed above: reduction in the real value of existing nominal government debt by unexpected inflation, increased seignorage revenues, and a reduced real debt service burden of the existing government debt, respectively.

In the simulation reported in Figure $1, \hat{\delta}_{t}$ increases by $2.33 \%$; this is balanced by an increase in the first term on the right-hand side of $1.01 \%$, an increase in the

\footnotetext{
${ }^{25}$ For example, Buiter et al. (1993) discuss the argument that Maastricht treaty's fiscal norms are needed for a European monetary union on the ground that "the new ECB [European Central Bank] will effectively be forced to monetize the budget deficits of countries without fiscal discipline." They argue that "the possibility seems remote. The Treaty is very clear about the 'independence' of the ECB, the primacy of the goal of 'price stability', and the elimination of any privileged financing of budget deficits by the ECB" (p. 80).
} 
second term of $0.22 \%$, and an increase in the third term on the right-hand side of $1.10 \%$. Thus only a rather small part of the total adjustment (nine percent of the total adjustment, in this simulation) comes about through an increase in seignorage revenues. The true fiscal significance of inflation - and hence the true reason why an exogenous primary deficit results in inflation in equilibrium - in the case of parameter values like these ones (intended to be realistic for a low-inflation country) relates instead to the capital losses that unexpected inflation causes on nominal government debt, and to the reduced debt service burden resulting from lower real interest rates.

Indeed, if we assume that the monetary base is negligible as a share of total government liabilities (by setting $\gamma=0$ in the above calculations), the simulation reported in Figure 1 is changed very little, though in this limiting case inflation results in no contribution to the government budget through seignorage revenues. In fact, leaving the other parameter values unchanged, the predicted increase in inflation in the first year is only slightly larger than in Figure 1 (about 1.1\%), and its persistence is also similar to that shown in Figure 1. Thus the mechanisms at work in these simulations are fully consistent with the fact that seignorage revenues are an unimportant part of government finances in low-inflation countries, and that monetary policy is not in fact made with seignorage revenues in mind.

\section{Constraints on the Public Debt and Fiscal Pol- icy Neutrality}

The results of the previous section allow an answer to the question posed in the title of this paper. Control of the government's budget is necessary for price stability, in a certain sense. It is not necessary for either the government budget deficit or the size of the public debt to be constant over time (let alone for either of them to be zero) in order for price stability to be possible; nor has any particular upper bound for either been shown to be necessary. But it has been shown that variations in the government budget can easily be a source of disturbances to the rate of inflation, and to interest rates and real activity as well; in particular, this has been shown to result if (as can easily be the case) fiscal shocks imply a change in the expected present value of the government budget over the indefinite future, at what would otherwise have been equilibrium rates of interest. In such a case, the fiscal shocks not only the disturb the price level if monetary policy is not adjusted in response to them; we have seen that they necessarily disturb the price level, regardless of the nature of the monetary policy response.

On the other hand, the kind of restrictions upon fiscal policy that are necessary in order to eliminate this source of macroeconomic instability are, in principle (and under the various idealized assumptions made in the model of section 1), not very severe. In particular, the path of the government budget over any finite horizon does not matter, as long as households can expect offsetting adjustments to eventually 
be made. This is because a "Ricardian equivalence" proposition does hold for this model, under a particular restriction on the character of fiscal policy.

I shall say that monetary policy is "autonomous" if it is described by an interestrate rule of the form

$$
i_{t}=\Phi\left(P_{t}, Y_{t}, M_{t}, P_{t-1}, Y_{t-1}, \ldots\right),
$$

where $\Phi$ does not explicitly depend upon any of the fiscal variables $\left\{B_{t}, G_{t}, T_{t}, B_{t-1}, \ldots\right\}$. Clearly, we cannot in general expect fiscal shocks to be irrelevant, except under such an assumption; otherwise, fiscal shocks may affect the economy, if only through their effects upon monetary policy. ${ }^{26}$ Note that the rule (2.4) considered in the previous section is an example of an autonomous policy in this sense; but the debt neutrality result to be stated here applies to a much broader class of monetary policies as well, including policies that involve a target path for the money supply.

And I shall call fiscal policy "Ricardian" if it is determined by a rule that adjusts the size of the real primary budget deficit $\left\{\Delta_{t}\right\}$ so as to prevent the real value of outstanding government debt from exploding, regardless of the paths of prices, interest rates, output, or the money supply. (I propose this terminology on the ground that the assumption that policy is of this kind is implicit in in familiar arguments for Ricardian equivalence.) To be precise, the fiscal policy rule is "Ricardian" if it implies that the path of outstanding government debt $\left\{B_{t}\right\}$ satisfies

$$
\lim _{T \rightarrow \infty} E_{t}\left[R_{t, T} B_{T}\right]=0
$$

regardless of the paths that may be followed by the non-fiscal variables just mentioned.

Under these two stipulations - that monetary policy be autonomous and that fiscal policy be Ricardian - one can show that the path of the government debt is irrelevant for the determination of macroeconomic equilibrium. To be precise, the set of processes $\left\{P_{t}, Y_{t}, i_{t}\right\}$ that constitute a rational expectations equilibrium, given the monetary policy rule, is independent of the specification of fiscal policy - except for the stipulation that it is Ricardian - and in particular, is independent of whether or not the government's budget varies in certain random states.

The reasoning may be sketched as follows. Given (3.2), equation (1.15) may equivalently be written

$$
\lim _{T \rightarrow \infty} E_{t}\left[R_{t, T} M_{T}\right]=0
$$

A rational expectations equilibrium is then a collection of processes $\left\{Y_{t}, C_{t}, G_{t}, T_{t}, B_{t}\right.$, $\left.M_{t}, R_{t, T}, i_{t}, P_{t}, \mathcal{P}_{t}, S_{t, T}\right\}$ that satisfy equations (1.9) - (1.12), (1.14), (1.16) - (1.18), $(3.1),(3.3)$, and the fiscal policy rule. ${ }^{27}$ Now suppose that $\left\{\bar{Y}_{t}, \bar{C}_{t}, \ldots\right\}$ represent an

\footnotetext{
${ }^{26}$ See Aiyagari and Gertler (1985) for an important early discussion of this.

${ }^{27}$ The fiscal policy rule includes a specification of $G_{t}$ and $T_{t}$ as functions of other current state variables, and a specification of the composition of the government debt. For example, in the policy regime considered in section $2,\left\{G_{t}\right\}$ is an exogenous stochastic process, $T_{t}$ is equal to $P_{t}$ times an exogenously evolving level of real tax collections, and the government debt consists entirely of riskless, one-period nominal bonds.
} 
equilibrium in the case of a particular Ricardian fiscal policy rule. $\mathcal{F}$, and consider instead an alternative fiscal policy rule $\mathcal{F}^{\prime}$. One can find a rational expectations equilibrium for $\mathcal{F}^{\prime}$ by leaving the processes $\left\{\bar{Y}_{t}, \bar{M}_{t}, \bar{R}_{t, T}, \bar{i}_{t}, \bar{P}_{t}, \overline{\mathcal{P}}_{t}, \bar{S}_{t, T}\right\}$ unchanged, and using equations (1.9), (1.14), and the fiscal policy rule to solve for the implied evolution of the variables $\left\{C_{t}, G_{t}, T_{t}, B_{t}\right\}$, given the processes $\left\{\bar{Y}_{t}, \bar{M}_{t}, \ldots\right\}$. These latter equations can in fact be solved for a very general class of fiscal policy rules; and given such a solution, the remaining equilibrium conditions are necessarily satisfied as well, since none of them involve the variables $\left\{C_{t}, G_{t}, T_{t}, B_{t}\right\}$.

Under such circumstances, fiscal policy disturbances cannot be a necessary cause of price level instability, as in the simulations of section 2. For if price stability is consistent with any Ricardian fiscal policy - say, with a fiscal policy that results in zero government debt at all times - then it is consistent with every Ricardian fiscal policy, including Ricardian rules that involve random variations in the government budget and in the path of the public debt, without, however, violating (3.2).

One can furthermore show that in the case of a Ricardian fiscal policy, it is possible to choose a monetary policy rule (3.1) that is consistent with price stability, even if household preferences are subject to random variation, and the government budget is also subject to exogenous stochastic shocks. In order to find a monetary policy that is consistent with $P_{t}=P^{*}$ forever (for an arbitrary choice of $P^{*}>0$ ), one simply solves equations (1.10) - (1.12) and (1.16) - (1.18) for the processes $\left\{Y_{t}, M_{t}, R_{t, T}, i_{t}, \mathcal{P}_{t}, S_{t, T}\right\}$ that are consistent with the constant price level $P^{*}$. (As discussed at the beginning of section 2, these equations have a unique solution when preferences are not subject to stochastic disturbances; they will continue to have a solution in the case of a broad class of disturbances.) One must verify that the solution satisfies (3.3). (Again, this is necessarily true in the unperturbed case, and will continue to be true in the case of a broad class of preference shocks.) Monetary policy may then be specified by setting the nominal interest rate $\left\{i_{t}\right\}$ equal to the (possibly state-contingent) process just solved for (or, alternatively, setting the money supply $\left\{M_{t}\right\}$ equal to the process just solved for). The processes $\left\{C_{t}, G_{t}, T_{t}, B_{t}\right\}$ are then determined by equations (1.9), (1.14), and the fiscal policy rule, as above.

Neither of these two conclusions held in the example of section 2, because the fiscal policy assumed there (an exogenous stochastic process for the real primary deficit) was not Ricardian. This does not mean the fiscal policy assumed there necessarily violates (3.2); to the contrary, (3.2) holds in the equilibrium that is constructed above. But the fiscal policy rule is not Ricardian, because it (together with the government's flow budget constraint (1.14)) would imply an explosive path for the government debt, violating (3.2), under other possible paths of prices and interest rates, that happen not to be those that obtain in equilibrium - in particular, (3.2) would be violated in the case of a constant price level, and the associated constant level of interest rates, which is why this cannot be a rational expectations equilibrium under that policy. The relevant distinction here, between Ricardian and non-Ricardian fiscal policies, is thus not the same as the common distinction between "sustainable" and 
"unsustainable" fiscal policies. A non-Ricardian policy is one for which (3.2) does not hold as an identity, as a consequence of the fiscal policy rule; but there may exist price-level and interest-rate processes that result in (3.2) being satisfied under such a policy, and thus a non-Ricardian policy need not be inconsistent with the existence of rational expectations equilibrium, or a policy that must necessarily be expected to be abandoned at some future date.

Discussions of Ricardian equivalence generally take (3.2) for granted, and thus arrive at a fiscal policy neutrality proposition of the kind stated above, without any qualification as to the nature of fiscal policy. ${ }^{28}$ Condition (3.2) is indeed generally a necessary condition for a rational expectations equilibrium - for it follows from the transversality condition (1.15) for household optimization, under any regime in which the government debt is at all times non-negative. But this does not mean that a policy rule must guarantee that (3.2) holds in order for that policy rule to be consistent with existence of an equilibrium. In order for a fiscal policy to be consistent with existence of an equilibrium, there must be prices and interest rates at which the public would choose to hold the debt that the government issues, but this need not be true for all possible prices and interest rates. Under a non-Ricardian fiscal policy rule (that implies a non-negative public debt), condition (3.2) is an equilibrium condition, but it is not an identity. ${ }^{29}$ As a consequence, fiscal policy is not inevitably neutral in its effects upon inflation, interest rates and economic activity, though that neutrality can be assured (under the various idealized assumptions of the model of section 1 ) if the government commits itself to ensuring that (3.2) will hold.

What kind of constraint upon the nature of fiscal policy is needed in order to eliminate the source of macroeconomic instability illustrated in section 2? Plainly, nothing so severe as annual budget balance is needed. It suffices that fiscal policy be Ricardian (assuming that households understand this to be the case, and so do not change their expectations regarding their intertemporal budget constraint (1.13) as a result of a disturbance to the government budget in a particular year), and this is only a constraint upon the asymptotic behavior of the public debt. It thus might seem that constraints upon the size that deficits or the public debt may reach in the near term are completely unjustified as a response to this concern.

However, a government's commitment to a Ricardian policy cannot easily be made

\footnotetext{
${ }^{28}$ Discussions of Ricardian equivalence in monetary economies do generally contain a qualification regarding the possible effect of fiscal policy upon monetary policy; for example, the proposition stated by Sargent (1987, Prop. 5.3) applies only to fiscal changes that leave unchanged the path of the money supply. This, however, is the qualification expressed above in our stipulation that monetary policy be "autonomous"; Sargent takes (3.2) for granted and is concerned only to exclude the possibility that a fiscal change affects the price level through its effect upon monetary policy. But the violation of Ricardian equivalence illustrated in section 2 is not a consequence of a monetary policy that allows the money supply to be endogenous (a case not allowed by Sargent's proposition), for in fact Ricardian equivalence holds for autonomous monetary policies more generally, when fiscal policy is Ricardian.

${ }^{29}$ See Woodford (1995) for further discussion of this issue.
} 
credible to the public, if the commitment does not in any way constrain the path of the public debt over, say, the next twenty years. Thus acceptance of a commitment to constrain the path of the government budget deficit and/or the level of the public debt, in the near term as well as later, is probably necessary in order to obtain the benefits of fiscal neutrality, even though such a constraint is tighter than would be necessary for a policy to be Ricardian. ${ }^{30}$ In fact, a commitment to a ceiling upon the real level of the public debt, like the debt guideline set out in the Maastricht treaty, would seem a plausible way of eliminating the type of fiscal disturbances illustrated in section 2. On the one hand, such a limit allows considerable variation from year to year in the degree of government budget balance, as long as deficits in some years are balanced by a sufficient number of surpluses in other years to keep the public debt from ever exceeding the ceiling; and since our analysis implies that such year to year variations in the government's budget need pose little threat to price stability, it seems reasonable to allow them (to simplify fiscal planning, to allow for tax smoothing on efficiency grounds, and - in the context of the European monetary union - to minimize the necessary interference of the central authority with individual countries' fiscal policies.)

On the other hand, a ceiling for the real value of the public debt,

$$
B_{t} / P_{t} \leq \bar{b}
$$

for all $t$, does suffice to guarantee that (3.2) must hold for many price-level and interest-rate paths (for example, any in which the real rate of return remains bounded above zero forever). Under such circumstances, (3.2) may not be quite an identity, but at any rate places only very weak restrictions upon possible equilibrium paths. In particular, a constant price level and the associated constant interest rate (as discussed at the beginning of section 2) will imply that (3.2) is satisfied, given such a constraint. This means that in the model of section 2 , with the monetary policy rule assumed there and a fiscal policy that guarantees that (3.4) holds, a rational expectations equilibrium will exist with stable prices. ${ }^{31}$ Furthermore, in the case

\footnotetext{
${ }^{30}$ The theoretical analysis here gives no grounds for choice among alternative fiscal policy rules that share the property of being Ricardian; indeed, the irrelevance proposition just stated implies that, under the idealized assumption made here, all such policies are equivalent in their consequences for price stability and for macroeconomic stability more generally. The practical choice would depend upon elements abstracted from in this model: reasons for a government to care about policy flexibility on the one hand, and reasons why it is difficult to establish credibility with the public on the other. Both of these issues are obviously of considerable importance for practical policy choice, and there would seem to be a tension between them: for it is easiest to establish credibility if the government commits itself to a tough requirement, that thereby allows the government frequent opportunities to show that it is serious about the commitment. Analysis of this trade-off is beyond the scope of this paper.

${ }^{31}$ This does not mean that this is the only rational expectations equilibrium consistent with such policies. But the existence of stochastic fluctuations in the government budget from year to year will not interfere with this equilibrium, and one may suppose that it will be possible under such circumstances to lead the public to expect prices to be stable.
} 
of (a very large class of possible) stochastic disturbances to household preferences, there will continue to exist a monetary policy rule that makes a rational expectations equilibrium with stable prices possible, as long as the fiscal policy rule guarantees (3.4). For in the absence of preference shocks, the discount factors implied by (1.10) in the case of a constant price level are given by $R_{t, T}=\beta^{T-t}$. Even with preference shocks, it will continue to be the case, for a large class of such disturbances, that the implied discount factors satisfy

$$
\lim _{T \rightarrow \infty} R_{t, T}=0
$$

which is sufficient, together with (3.4), to imply (3.2). ${ }^{32}$

Thus a constraint upon fiscal policy is needed, even when the independence of the central bank is absolute and its concern for price stability undoubted, if price stability is to be possible. And while this need not take the form of a ceiling of the form (3.4) for the growth of the public debt, ${ }^{33}$ such a restriction is a simple example of a rule that should suffice, and that has the advantage of being a commitment that is easily explained to the public, and that may be observed to affect policy choices over a finite horizon. In this way, the Maastricht guidelines do eliminate a source of price level instability that might easily be important in their absence.

This does not, of course, imply that the precise formulation of the guidelines given in the Maastricht treaty is necessarily the best one. The main reason why the Maastricht guidelines pose a serious obstacle to many of the signatory nations' participation in the envisioned monetary union is the limits placed on their public debts and budget deficits between now and 1999, which in many cases would require severe fiscal adjustment over a very short time horizon. The required adjustment would be very painful for these countries, even though in many cases the countries already project more gradual fiscal adjustments that imply that their policies would satisfy the transversality condition (3.4), if currently projected government budgets were to be extrapolated into the future (Uctum and Wickens, 1996). Since our analysis implies that it suffices that governments commit themselves to satisfy (3.4), it provides no justification for the much more onerous requirement of significant adjustment by 1999, except to the extent that immediate adjustment is necessary in order for a government to make credible its commitment to the longer-term goal. In particular, this analysis suggests that it would be appropriate to place more stress on the commitment to control of one's public debt after admission to the monetary union than in the period leading up to formation of the union. ${ }^{34}$ The analysis here also provides no defense for the Maastricht guidelines' emphasis upon gross as opposed

\footnotetext{
${ }^{32}$ Here I assume also that the fiscal policy rule implies non-negative government debt at all times.

${ }^{33}$ See Bergin (1995) for discussion of other types of fiscal rules that suffice to imply condition (3.2).

${ }^{34}$ The treaty does provide for monitoring of member countries' deficits and public debt after the formation of the union (Kenen, 1995, chap. 4). However, concern is sometimes expressed that the enforcement provisions associated with the monitoring that is envisaged after entry into the union are comparatively weak (Issing, 1995).
} 
to net debt, or upon their use of a debt measure that does not count government pension obligations (aspects of the Maastricht guidelines that are sensibly criticized by Buiter et al., 1993).

\section{Public Debt and Price Stability in a Monetary Union}

Let us now consider the consequences of the above analysis for the design of a monetary union. Suppose that a group of countries use a common currency, issued by a common central bank. Does it suffice for price stability in the union that the common central bank pursue a steady, non-inflationary monetary policy, with fiscal policy left to the discretion of the individual countries? Or is coordination of fiscal policy necessary as well?

We can consider this issue in the context of a model of a two-country monetary union. Suppose, as in section 1, that there is a continuum of households indexed by $j \in[0,1]$, but that these households are not all taxed by the same government, nor does the same government supply public goods for all of them. Instead, let households $j \in J_{1}=[0,1 / 2]$ belong to "country 1 ", while households $j \in J_{2}=(1 / 2,1]$ belong to "country 2". The government of each country $i$ levies lump-sum taxes in the amount of $2 T_{t}^{i}$ per household in period $t$, upon each of the households in $J_{i}$, and produces public goods in the quantity $G_{t}^{i}$ in period $t$, which public goods benefit only the households in $J_{i}$. (Note that taxes due per household are $2 T_{t}^{i}$, so that total tax revenues of government $i$ are $T_{t}^{i}$.) Let the technology for production of public goods by each country be the same CES technology as in section 1, so that all of the goods produced in each country are used by both governments, and the cost of public goods provision is the same at all times for both governments (and given as before by the price index $P_{t}$ defined in (1.3)). Each government issues public debt denominated in units of the common currency. Finally, let us assume as in section 2 that each government issues only riskless, nominal one-period debt. Let $B_{t}^{i(t o t)}$ denote the nominal value (in units of the common currency) of the public debt of country $i$ at the beginning of period $t$, counting both debt in the hands of the public (of either country) and debt held by the common central bank. This quantity then evolves according to the flow budget constraint

$$
B_{t+1}^{i(t o t)}=\left(1+i_{t}\right)\left[B_{t}^{i(t o t)}+P_{t} \Delta_{t}^{i}\right]
$$

where $i_{t}$ is the common nominal interest rate for both countries, and $\Delta_{t}^{i} \equiv G_{t}^{i}-T_{t}^{i} / P_{t}$ is the real primary deficit of country $i$ in period $t$.

Each household receives liquidity services, as before, from holding the common currency. This currency is supplied by the central bank in whatever quantity the households of the two countries wish to hold, at the level of short-term nominal interest rates fixed by the central bank's monetary policy. Monetary policy is again 
assumed to be described by a policy rule of the form (2.4). The interest rate is controlled through exchanges of currency for bundles consisting of an equal quantity of bonds issued by the two governments; this bundle constitutes the only asset in terms of which the central bank conducts open market operations. Since the central bank's holdings of the two governments' bonds also earn the same interest rate at all times, the values of the central bank's holdings of the two countries' debt are always the same. Letting $B_{t}^{i(C B)}$ denote the nominal value at the beginning of period $t$ of the central bank's holdings of the debt of country $i$, we have $B_{t}^{1(C B)}=B_{t}^{2(C B)}$ at all times. The evolution of the central bank's holdings of either kind of debt must furthermore be related to the path of the money supply through the relation

$$
B_{t+1}^{i(C B)}=\left(1+i_{t}\right)\left[B_{t}^{i(C B)}+\frac{1}{2}\left(M_{t}-M_{t-1}\right)\right],
$$

where $M_{t}$ is the total supply of the common currency at the end of period $t$. Combining (4.1) and (4.2), we observe that the debt of country $i$ in the hands of the public, $B_{t}^{i} \equiv B_{t}^{i(t o t)}-B_{t}^{i(C B)}$, evolves according to the law of motion

$$
B_{t+1}^{i}=\left(1+i_{t}\right)\left[B_{t}^{i}+P_{t} \Delta_{t}^{i}-\frac{1}{2}\left(M_{t}-M_{t-1}\right)\right] .
$$

This equation generalizes the flow budget constraint (2.5) for the single-country case. 35

Household objectives and budget constraints remain as in section 1, except that in the household objective function (1.1), $G_{t}$ must be replaced by $2 G_{t}^{i}$ for all $j \in J_{i}$, and in the intertemporal budget constraint (1.6), $T_{t}$ must be replaced by $2 T_{t}^{i}$ for all $j \in J_{i}$. (The factors of 2 appear because these are the per household levels of government purchases and tax obligations.) With these modifications, the necessary and sufficient conditions for optimization presented in section 1 continue to apply.

Now, as households in both countries have the same preferences (for "total" consumption $\left\{C_{t}^{j}+2 G_{t}^{j}\right\}$, rather than for private consumption alone) and face the same prices, rates of return, and demand for their products, it is clear that households in both countries would choose at all times the same level of "total" consumption, the same level of money balances, and the same prices for their goods, if their initial wealths were such as to allow them identical lifetime budget sets, and they begin with the same distribution of existing prices for the goods that they supply. (This does not mean an initial wealth $W_{0}^{j}$ identical for all households, but rather that initial wealths are different, between the two countries, to exactly the extent needed to offset any differences that may exist with respect to the expected fiscal policies of the two governments, as well as differences in expected revenues due to differing initial prices.)

\footnotetext{
${ }^{35}$ Note that (4.3) could equivalently be derived by assuming that the central bank distributes its seignorage revenues to the two governments, in fixed 50-50 shares. Under the operating rules described here, the central bank is in effect helping to finance the two governments by accumulating their debt and never seeking repayment; the extent to which the two governments share in the subsidy depends upon the extent to which the central bank accumulates each type of debt.
} 
Again, our analysis is simplified if we assume that initial wealths are such that this is so.

We thus consider an equilibrium in which

$$
C_{t}^{1}+2 G_{t}^{1}=C_{t}^{2}+2 G_{t}^{2}
$$

at all times, where for each country $C_{t}^{i}$ denotes the common index of private consumption, defined in (1.2), for all households in country $i$. We may let this common level of "total" consumption be denoted $Y_{t}$; it is just the index of aggregate demand defined in equation (1.9) - which is still valid if we now define $G_{t} \equiv G_{t}^{1}+G_{t}^{2}$ - and that appears in the demand functions (1.8) for the differentiated goods. In such an equilibrium, money holdings are also identical for all households at all times, and may thus be simply denoted $M_{t}$. Households in both countries have an identical marginal cost of production defined by (1.17), in the case of goods with the same price; it thus follows that the optimal price $\mathcal{P}_{t}$ for goods that receive a new price at date $t$, is the same in both countries. Hence the evolution of the price index $P_{t}$ defined in (1.3) continues to be described by (1.18). The first-order conditions for household optimization continue to be given by equations (1.10) - (1.12) and (1.16) - (1.17).

The only condition for household optimization in section 1 that does not apply equally in the two-country model is (1.13). This condition now takes the form

$$
\sum_{T=t}^{\infty} E_{t}\left\{R_{t, T}\left[P_{T} C_{T}^{i}+\frac{i_{T}}{1+i_{T}} M_{T}\right]\right\}=\sum_{T=t}^{\infty} E_{t}\left\{R_{t_{1} T}\left[P_{T} Y_{T}-2 T_{T}^{i}\right]\right\}+W_{t}^{i}
$$

for each household $j \in J_{i}$, where $W_{t}^{i}$ represents per capita financial wealth of the households in $J_{i}$. (Note that the aggregate wealth of households in country $i$ need not coincide with the value of total outstanding liabilities of government $i$.) Subtracting the sum on the right-hand side of (4.4) from both sides of the equation yields

$$
\sum_{T=t}^{\infty} E_{t}\left\{R_{t, T}\left[\frac{i_{T}}{1+i_{T}} M_{T}-2 P_{T} \Delta_{T}^{i}\right]\right\}=W_{t}^{i} .
$$

Integrating both sides of (4.5) over all households yields, finally,

$$
\sum_{T=t}^{\infty} E_{t}\left\{R_{t, T}\left[\frac{i_{T}}{1+i_{T}} M_{T}-P_{T} \Delta_{T}\right]\right\}=M_{t-1}+B_{t}
$$

where $\Delta_{t} \equiv \Delta_{t}^{1}+\Delta_{t}^{2}$ is the consolidated real primary deficit of the two countries, $B_{t} \equiv B_{t}^{1}+B_{t}^{2}$ is their aggregate public debt, and where we have made use of the bond market equilibrium condition ${ }^{36}$

$$
\int_{0}^{1} W_{t}^{j} d j-M_{t-1}=B_{t}
$$

\footnotetext{
${ }^{36}$ Note that there is a zero net supply of all financial assets other than the riskless nominal bonds issued by the two governments, even though each country may have non-zero aggregate holdings of other types of contingent claims, in order to achieve the risk pooling discussed above.
} 
Now condition (4.6), which is equivalent to (1.13) of the single-country model, would be a requirement for equilibrium even if we did not assume that households in both countries can afford the same level of "total" consumption; the additional requirement in the latter case is that (4.5) hold for each country individually. The assumption made earlier about the initial wealth distribution is that $W_{0}^{1}, W_{0}^{2}$ be such that be such that (4.5) holds for each country, rather than only when one aggregates across the two countries. Given, however, an initial wealth distribution of this kind, we need make no further reference to conditions (4.5) in our characterization of equilibrium; only the aggregate public debt of the union, $\left\{B_{t}\right\}$, and the consolidated deficit $\left\{\Delta_{t}\right\}$ matter for the determination of the equilibrium paths of inflation, interest rates, and output.

A complete system of equations for the determination of rational expectations equilibrium is then given by (1.10) - (1.12), (1.16) - (1.18), (2.4), and (4.6). Note that these are exactly the same equations as determine the equilibrium paths of the variables $\left\{P_{t}, \mathcal{P}_{t}, Y_{t}, i_{t}, M_{t}, B_{t}\right\}$ in the single-country model, except that now the variable $\left\{\Delta_{t}\right\}$ is the consolidated deficit of the two governments, rather than that of a single government. It follows that the analysis in sections 2 and 3 above again applies. If both countries follow Ricardian fiscal policy rules, then changes in the path of either country's public debt has no effects upon inflation, interest rates, or output. However, if either has a non-Ricardian policy, then fiscal shocks in that country will generally imply a disturbance to inflation, interest rates, and output in both countries - since the latter variables all co-move perfectly in the two countries.

In particular, if each country chooses an exogenous process for $\left\{\Delta_{t}^{i}\right\}$, then the consequences are as in section 2, except that it is only the consolidated deficit $\left\{\Delta_{t}\right\}$ that matters for the determination of inflation and so on. It follows that even if one government is fiscally responsible, and keeps its real primary deficit at some sustainable constant level, variations in the budget deficit of the other government will result in price level instability for that government as well. Thus there is a clear reason for a government concerned to maintain stable prices to care about the fiscal policies of other governments with which it shares a common currency.

Note that in an equilibrium of the kind just described, (1.15) again holds, where $W_{t} \equiv\left(W_{t}^{1}+W_{t}^{2}\right) / 2=M_{t-1}+B_{t}$ denotes aggregate financial wealth of the two countries. In the case of an equilibrium in which the aggregate government debt of the countries of the union is always non-negative, this implies that

$$
\lim _{T \rightarrow \infty} E_{t}\left\{R_{t, T} B_{T}\right\}=0
$$

But the same is not true, in general, for the present value of each country's public debt individually. ${ }^{37}$ Suppose that in country 1 , the primary deficit is forever constant, at a level $\Delta^{*} / 2$ consistent with stable prices, while in country 2 , there is a larger deficit,

\footnotetext{
${ }^{37}$ Here I disagree with the analysis of Bergin (1995), that imposes as an equilibrium condition a condition like (4.6) for each country individually.
} 
$\Delta_{t}^{2}=\Delta^{*} / 2+\epsilon$ in period $t$, for some $\epsilon>0$, with $\Delta_{T}^{2}=\Delta^{*} / 2$ at all other dates $T \neq t$. As prices, interest rates, and seignorage revenues are the same for both countries in each period, it follows from (4.3) that

$$
E_{t}\left\{R_{t T}\left[B_{T}^{2}-B_{T}^{1}\right]\right\}=P_{t} \epsilon
$$

for all $T>t$. Thus the present value of the public debt cannot approach zero asymptotically for both countries. Instead, in the case of an equilibrium for which (4.7) holds, one has

$$
\begin{gathered}
\lim _{T \rightarrow \infty} E_{t}\left\{R_{t, T} B_{T}^{2}\right\}=P_{t} \epsilon / 2, \\
\lim _{T \rightarrow \infty} E_{t}\left\{R_{t, T} B_{T}^{1}\right\}=-P_{t} \epsilon / 2 .
\end{gathered}
$$

This means that the outstanding public debt of country 2 grows at the rate of interest forever, while the government of country 1 becomes a net creditor, with the amount credit extended by that government similarly growing at the rate of interest forever. In effect, the government of country 1 lends to that of country 2, purchasing a quantity $P_{t} \epsilon / 2$ of the debt issued by government 2 at date $t$, and rolling the loan over forever, never demanding repayment. ${ }^{38}$ It does this as a result of a fiscal policy that requires it to run the same size of primary surplus forever, regardless of the fact that the deficit of government 2 in period $t$ results in inflation and a reduced real rate of return, thus reducing the size of the real surplus needed to service the existing debt of government 1.

Now it may seem unrealistic that the government of country 1 should follow a fiscal policy of this sort, in the face of the consequences just mentioned. Instead, one might suppose that a government that finds that it has paid off all of its debt and is even accumulating a growing stock of financial assets will reduce the size of its budget surplus. But refusal on the part of government 1 to "cooperate" in financing the profligacy of government 2 would not diminish the effects of fiscal instability in country 2 upon prices, interest rates and output in the two countries. Instead, the pursuit of a Ricardian policy by a fiscally responsible government actually amplifies the macroeconomic disturbances originating in changes in the present value of the partner's government budget.

Let us restrict our attention to equilibria in which (4.7) holds. ${ }^{39}$ Then condition (4.6) can equivalently be written

$$
\sum_{T=t}^{\infty} E_{t}\left\{R_{t, T}\left[\left(M_{T}-M_{T-1}\right)-P_{T} \Delta_{T}\right]\right\}=B_{t} .
$$

\footnotetext{
${ }^{38}$ Note that government 1 need not actually lend to government 2; it may lend to the households of country 1 , who borrow from their government in order to accumulate the debt issued by the other government.

${ }^{39}$ Note that this would always have to be the case if we consider only equilibria involving fluctuations around a deterministic growth path, as in section 2 .
} 
Furthermore, if government 1 follows a Ricardian fiscal policy, this ensures that

$$
\sum_{T=t}^{\infty} E_{t}\left\{R_{t, T}\left[\frac{1}{2}\left(M_{T}-M_{T-1}\right)-P_{T} \Delta_{T}^{1}\right]\right\}=B_{t}^{1}
$$

regardless of the path of prices and interest rates. (The factor $1 / 2$ enters as the money holdings of households in country 1 equal $M_{t} / 2$.) In this case equilibrium condition (4.6) reduces to

$$
\sum_{T=t}^{\infty} E_{t}\left\{R_{t, T}\left[\frac{1}{2}\left(M_{T}-M_{T-1}\right)-P_{T} \Delta_{T}^{2}\right]\right\}=B_{t}^{2}
$$

Note that while (4.8) holds regardless of the paths of prices and interest rates, as a result of the rule that determines the path of $\left\{\Delta_{t}^{1}\right\},(4.9)$ is a restriction upon the paths of those variables, given an exogenous process for $\left\{\Delta_{t}^{2}\right\}$.

Now, equilibrium condition (4.9) might equivalently be written

$$
\sum_{T=t}^{\infty} E_{t}\left\{R_{t, T}\left[\left(M_{T}-M_{T-1}\right)-2 P_{T} \Delta_{T}^{2}\right]\right\}=2 B_{t}^{2}
$$

But this is exactly the form that (4.6) takes in the case that the fiscal policy rule of government 1 is given by $\Delta_{t}^{1}=\Delta_{t}^{2}$ at all times, so that $B_{t}^{1}=B_{t}^{2}$ at all times as well. That is, adherence to a Ricardian policy by government 1 has the same effects as if government 1 were to vary its own budget in perfect lock-step with that of government 2 , so that the public debts of both countries always grow at exactly the same rate. This would mean that whenever government 2 reduces the present value of its budget surplus, government 1 reduces its own as well, by the same amount, thus doubling the inflationary impact of the expansionary fiscal policy on the part of government 2 . Intuitively, if government 1 chooses not to "cooperate" by financing some of the budget deficit of government 2 , then prices and interest rates must adjust even more in order to restore equilibrium between private sector purchasing power and the quantity of output available for households to purchase.

The only way that government 1 can act in order to minimize the macroeconomic instability resulting from fiscal instability in country 2 is for it to adjust the size of its own budget deficit inversely with that of government 2 , for example, by choosing

$$
\Delta_{t}^{1}=\Delta^{*}-\Delta_{t}^{2}
$$

at all times. ${ }^{40}$ As long as the present value of the consolidated government budget never changes, no macroeconomic instability will result from variation in the composition of the total public debt as to country of issuance. However, such a policy

\footnotetext{
${ }^{40} \mathrm{It}$ is actually not necessary that government 1 adjust its budget simultaneously with that of government 2. What matters is that government 1 always reduce the present value of its future deficits by exactly the same amount as the present value of the deficits of government 2 has increased; this could be accomplished entirely through reductions in the deficit of government 1 in subsequent periods to the time at which the deficit of government 2 increases.
} 
means that whenever the deficit of government 2 increases by an amount $\epsilon>0$ (without any offsetting expected reduction in future deficits), government 1 reduces the present value of its own planned deficits by exactly that amount. This is equivalent to government 1 financing all of the increased deficit of government 2 , by purchasing the debt issued by government 2 and never asking for repayment. But a commitment to do this would, of course, mean extending a "blank check" to government 2 , to run as large a deficit as it may please, with the assurance that government 1 will pay for it. This would clearly be an unacceptable arrangement from the point of view of the citizens of country 1 .

We thus may conclude that a country that consents to share a common currency with another does indeed expose itself to price level instability, and to the fluctuations in economic activity that follow from this, resulting from fiscal instability in the other country, if the partner is left free to follow a non-Ricardian fiscal policy. This is true even when the common central bank is perfectly independent of political pressures, and commits itself to a monetary policy rule that is completely independent of fiscal developments in either country. The common currency allows fiscal instability in one country to affect the value of the currency used by the other countries, even when they are models of fiscal probity themselves. But even worse, the existence of the common currency increases the temptations of reckless fiscal policy, as it allows the profligate government an opportunity to redistribute wealth away from the citizens of its fiscally responsible partners and toward its own; the partners can protect themselves from this only by choosing fiscal policies that match the recklessness of the profligate, and that therefore amplify the price level and output fluctuations resulting from fiscal instability in that country. For these reasons, it is obvious that a country contemplating such a monetary union should care about the fiscal policy of its partners.

Explicit constraints upon member countries' fiscal policies provide an obvious solution to this problem. Detailed coordination of fiscal policy among the members of a monetary union would not be necessary, at least not under the idealized assumptions of the model presented here. Instead, commitment on the part of all member countries to maintain the values of their respective public debts forever within some finite ceiling (a multiple of each country's GDP), as envisioned in the Maastricht treaty, would seem to be sufficient, if such a commitment can be made sufficiently credible. 


\section{REFERENCES}

Aiyagari, S. Rao, and Mark Gertler, "The Backing of Government Bonds and Monetarism," Journal of Monetary Economics 16: 19-44 (1985).

Barro, Robert J., "Are Government Bonds Net Wealth?" Journal of Political Economy 82: 1095-1117 (1974).

- - -, "The Neoclassical Approach to Fiscal Policy," in R.J. Barro, ed., Modern Business Cycle Theory, Cambridge, Mass.: Harvard University Press, 1989.

Bergin, Paul R., "Fiscal Restrictions in a Currency Union: Further Lessons on the Interactions of Monetary and Fiscal Policies," unpublished, Yale University, April 1995:

Blanchard, Olivier J., and Charles M. Kahn, "The Solution of Linear Difference Equations under Rational Expectations," Econometrica 48: 1305-1313 (1980).

Blanchard, Olivier J., and Nobuhiro Kiyotaki, "Monopolistic Competition and the Effects of Aggregate Demand," American Economic Review 77: 647-666 (1987).

Brock, William A., "Money and Growth: The Case of Long-Run Perfect Foresight," International Economic Review 15: 750-777 (1974).

Buiter, Willem, Giancarlo Corsetti, and Nouriel Roubini, "Excessive Deficits: Sense and Nonsense in the Treaty of Maastricht," Economic Policy 16: 57100 (1993).

Calvo, Guillermo A., "Staggered Prices in a Utility-Maximizing Framework," Journal of Monetary Economics 12: 383-398 (1983).

Clarida, Richard, and Mark Gertler, "How the Bundesbank Conducts Monetary Policy," unpublished, Columbia University, October 1995.

Dixit, Avinash K., and Joseph E. Stiglitz, "Monopolistic Competition and Optimum Product Diversity," American Economic Review 67: 297-308 (1977).

Issing, Otmar, "EMU Forces Hard Choices on Europe's Future," Wall Street Journal Europe, March 22-23, 1996.

Kenen, Peter B., Economic and Monetary Union in Europe: Moving Beyond Maastricht, Cambridge: Cambbridge University Press, 1995.

Kimball, Miles S., "The Quantitative Analytics of the Basic Neomonetarist Model," Journal of Money, Credit and Banking 27: 1241-1277 (1995).

King, Mervyn, "Commentary: Monetary Policy Implications of Greater Fiscal Discipline," in Budget Deficits and Debt: Issues and Options, Federal Reserve Bank of Kansas City, 1995.

King, Robert G., and Mark W. Watson, "System Reduction and Solution Algorithms for Singular Linear Difference Systems Under Rational Expectations," unpublished, University of Virginia, May 1995.

- - and $-\ldots$, "Money, Prices, Interest Rates and Business Cycles," 
Review of Economics and Statistics, forthcoming (1996).

King, Robert G., and Alexander L. Wolman, "Inflation Targeting in a St. Louis Model of the 21st Century," unpublished, University of Virginia, September 1995.

Leeper, Eric, "Equilibria Under 'Active' and 'Passive' Monetary Policies," Journal of Monetary Economics 27: 129-147 (1991).

Obstfeld, Maurice, and Kenneth Rogoff, "Exchange Rate Dynamics Redux," Journal of Political Economy 103: 624-660 (1995).

Roberts, John, "New Keynesian Economics and the Phillips Curve," Journal of Money, Credit and Banking 27: 975-984 (1995).

Sargent, Thomas J., Dynamic Macroeconomic Theory, Cambridge, Mass.: Harvard University Press, 1987.

_ - _ and Neil Wallace, "Some Unpleasant Monetarist Arithmetic," Quarterly Review, Federal Reserve Bank of Minneapolis, Fall 1981. [Reprinted in $R a$ tional Expectations and Inflation, 2d ed., New York: HarperCollins College Publishers, 1993.]

Sidrauski, Miguel, "Rational Choice and Patterns of Growth in a Monetary Economy," American Economic Review 57(2): 534-544 (1967).

Sims, Christopher A., "A Simple Model for the Determination of the Price Level and the Interaction of Monetary and Fiscal Policy," Economic Theory 4: 381-399 (1994).

- _ _ "Econometric Implications of the Government Budget Constraint," unpublished, Yale University, October 1995.

Svensson, Lars E.O., "Sticky Goods Prices, Flexible Asset Prices, Monopolistic Competition, and Monetary Policy," Review of Economic Studies 53: 385-405 (1986).

Taylor, John B., "Discretion Versus Policy Rules in Practice," Carnegie-Rochester Conference Series on Public Policy 39: 195-214 (1993).

Uctum, Merih, and Michael Wickens, "Debt and Deficit Ceilings, and Sustainability of Fiscal Policies: An Intertemporal Analysis," unpublished, Federal Reserve Bank of New York, April 1996.

Woodford, Michael, "Monetary Policy and Price Level Determinacy in a Cash-inAdvance Economy," Economic Theory 4: 345-380 (1994).

- - - "Price Level Determinacy Without Control of a Monetary Aggregate," Carnegie-Rochester Conference Series on Public Policy, 43:1-46 (1995).

Yun, Tack, "Nominal Price Rigidity, Money Supply Endogeneity, and Business Cycles," unpublished, University of Chicago, December 1994. 